\title{
A Review of Railway Feeding Infrastructures: Mathematical Models for Planning and Operation
}

\author{
Pablo Arboleya, Clément Mayet, Bassam Mohamed, José Antonio Aguado, Sebastián de la Torre
}

\begin{abstract}
In this paper, the authors review the mathematical models, simulation and analysis techniques and energy management systems proposed for railway power supply systems. The authors review both AC and DC railway feeding systems making special emphasis in those that consider new technologies like on-board or wayside energy storage, integration of renewable energies in the traction networks or the use of power electronic devices to increase the efficiency and controllability of the networks. The paper is divided in two main blocks studying DC and AC systems. In both parts, a review of the main simulation tools and models is presented but also a detailed list of specific cases of use of such techniques.
\end{abstract}

Index Terms-Electrical Railways, DC railways, AC railways.

\section{INTRODUCTION}

$\mathbf{R}$ AILWAY electric power feeding systems can be defined as the set of infrastructure and devices necessary to transport electrical energy from the conventional transport and distribution networks to the vehicles in a more or less efficient way. From this point of view, we could consider the railway feeding systems as distribution systems with special and distinctive characteristics. Its configuration depends in many cases on technical parameters but in other cases on historical decisions inherited and taken many decades ago. This has given rise to the fact that depending on when a certain route or a certain country has begun to be electrified, and on the technology available at that time, we have completely different power supply systems, AC systems at grid frequency, $\mathrm{AC}$ systems at low frequency or DC systems with different voltage levels. In [1], the authors review the most used configurations for feeding electrical railways considering $\mathrm{AC}$ and DC topologies. They also review the most important solutions based in power electronics to guaranty the power quality levels like for instance, balance transformers or power conditioners. A summary of the most used feeding systems in $\mathrm{AC}$ and DC network can be found in Fig. 1 based in a scheme presented in [2].

A common factor in railway power supply system manufacturers and operators has been their reluctance to switch from mature technologies to the introduction of new

Pablo Arboleya and Bassam Mohamed are with the LEMUR Research Group, Department of Electrical Engineering, University of Oviedo, Campus de Gijón, 33204, Spain, (e-mail: arboleyapablo@uniovi.es, mohamedbassam@uniovi.es)

Clément Mayet is with the SATIE Laboratorie and the Conservatoire National des Arts et Métiers of Paris, France (email: clement.mayet@lecnam.net)

José Antonio Aguado and Sebastian de la Torre are with the Escuela Técnica Superior de Ingeniería Industrial, Universidad de Málaga, Málaga, Spain (e-mail: jaguado@uma.es, storre@uma.es) technologies. Due to this fact, we can find systems with relatively modern trains equipped with bi-directional power converters that can implement functions such as regenerative braking but fed from electrical systems with relatively old technologies.

In recent years, the urgent necessity of improving the power quality of the systems and their efficiency and sustainability, combined with a global trend in electrification triggered the adoption of technologies not easy to find until now in conventional feeding systems. These technologies can go from conventional regenerative braking systems in the vehicles to very sophisticated combinations of wayside and on-board energy storage systems with embedded renewable generation and a wide catalog of power electronic solutions.

For this reason, it is necessary to adapt the conventional simulation tools in order to include new models representing the new technologies to be able to simulate new topologies

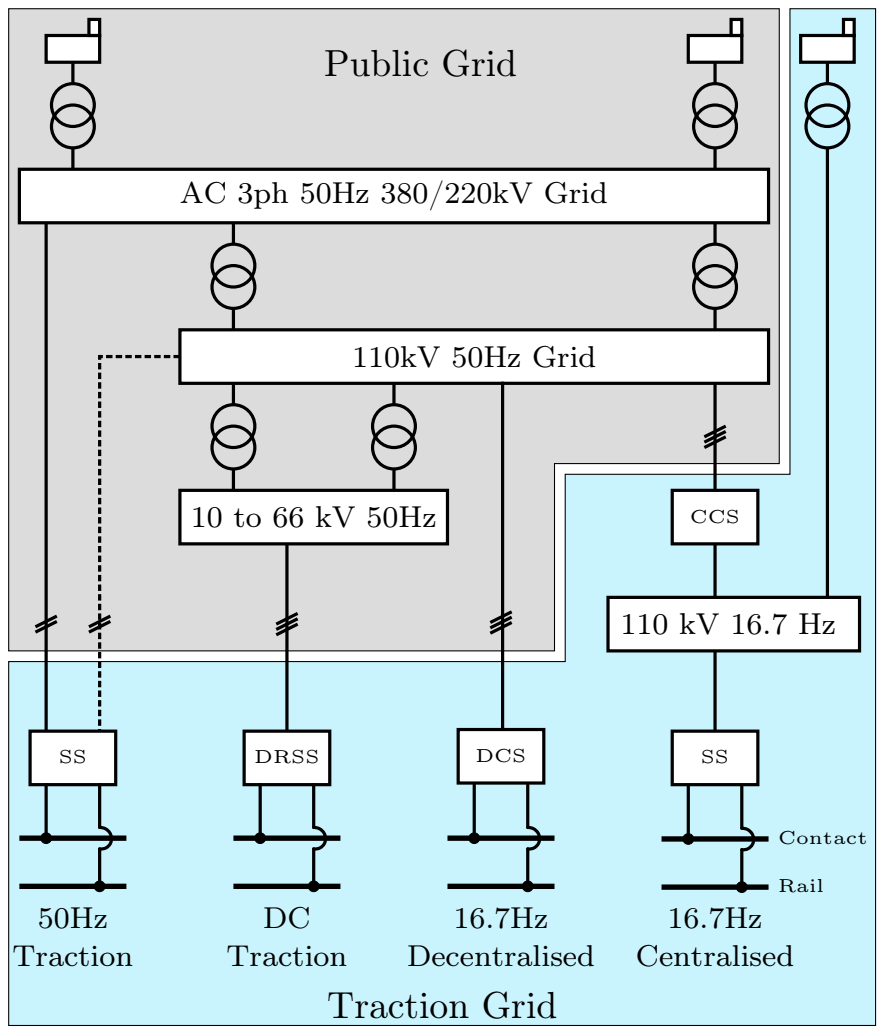

Fig. 1. Different traction network feeding systems [2]. Substation at $50 \mathrm{~Hz}$ or $16.7 \mathrm{~Hz}$ (SS), Decentralized rectifier substation (DRSS), Decentralized converter station at $16.7 \mathrm{~Hz}$ (DCS), Central converter station (CCS). 
and configurations. It is also necessary to develop models and methods for planning and operation purposes able to obtain more efficient operation strategies and more cost effective and sustainable solutions. It is also critical to increase the power quality of the electric traction systems and reduce their impact over the conventional distribution and transport networks that feed them.

We need to emphasize that railway feeding infrastructure is a very unique infrastructure with extremely specific features. In addition, the number of companies that develop, plan and operate these networks is quite reduced compared to those developing the same activities in conventional distribution networks. As a consequence, the number of commercial software for this purpose is really limited and these tools do not usually provide access to the mathematical models or the newest technological advances. In addition, many companies develop their own simulation tools [3]. Even when it is beyond the scope of this paper to provide a detailed list of the commercial tools related to this field, we will revisit here the most renowned tools and their capabilities. We can find in the markets many tools applied to railway operation, but many of them solve logistic problems with few or no connection at all with the electrical feeding systems [4]-[8]. Other solutions are very focused on the rolling-stock but with low emphasis in the distribution systems [9]. The case of the software package presented in [8] is one of the few commercial suites using mixed-integer-linear-optimization technology (MILP) for planning and scheduling rail operations.

Probably one of the most complete software tools in the market is OpenTrack [10], it has many modules that allow the user to calculate all kind of systems from high-speed rails to light rails, metro systems, maglev, mining railways, rack railways... The tool allows to determine the requirements of the infrastructure and calculate energy consumption of the trains among other calculations. In addition, when OpenTrack is combined with OpenPowerNet [11], it can run railway power supply system simulations like the ones studied in the body of this paper. A similar approach is the one offered by [12], in this case, the software offers a cloud based environment for simulation and modelling. SIGNON developed two software suites called Sinanet and Webanet to solve respectively DC and AC traction systems [13], both software are capable of running power flow analysis. eTraX module [14] from eTap [15] software is a unique solution since allows to run power flow simulations in $\mathrm{AC}$ and DC systems, but in this case including the interaction with the distribution network that feed the railway power supply. The software Traferr is only oriented to obtain the power consumption in the railway power substations [16].

In the present work, the authors review the most recent models and simulations applied to railway power supply systems in both DC and AC systems and provide a wide evaluation of cases of use of such models, tools and methodologies. It is true that we can find in the literature many other reviews in the field of railway systems, and more in recent years, since the technology in this kind of applications is suffering a drastic transformation. We revisit in this section the review works published in the field of electrical railways in recent years in the top ranked journals. As it can be observed, [1] is probably the most similar work when compared to the present paper, but in this case the paper is focused on describing power electronic technologies added to the power supply systems and it is only focused on describing the technologies but not the mathematical models and the simulation methods presenting such technologies. Something similar could be stated about reference [17] focused only in power electronic converters embedded in $\mathrm{AC}$ railway power supply systems and reference [18] just focused on wayside energy storage systems and their impact over the power supply network. Reference [19] is focused on describing power quality issues present in power supply systems and the work presented in [20] studies the substitution of conventional power transformers by power electronic transformers but mainly for rolling stock applications and not for power supply ones. The work presented in [21] reviews the most used parameters and techniques used to simulate high-speed rails and proposes a standard approach in order to perform the simulations, but only for high-speed AC railways. [22] is just focused on rolling stock power architectures and not in the power supply systems. The authors in [23] revise the fault detection and diagnosis techniques but just for $\mathrm{AC}$ railways. The case presenting in [24] is interesting because it deals with the electrification of the roads, many elements in these infrastructures are common with the railways, but of course, road electrification is beyond the scope of our paper. References [25], [26] review the best techniques for optimal train operation and control. We must emphasize that the work presented here is more general and focused on the supply systems and the techniques used to describe, model and simulate them. We consider all kind of power supplies and we cover all possible technologies applied to this infrastructure.

The paper is divided in two parts, the first one deals with DC systems while the latter describes AC simulation tools. In the next bullets the structure sections and subsections of the paper is provided:

\section{DC RAILWAy Power Supply Systems}

A) Development of Static Mathematical Models and Solvers

1) Decoupled Approaches

2) Integrated Approaches

B) Development of Dynamic Mathematical Models and Solvers

C) Specific Cases of Use of Different Simulation Tools and Models

1) Trajectory and Schedule Optimisation

2) Infrastructure Optimisation

3) Energy Management and Control

4) Hardware in the Loop Applications

5) Medium Voltage DC (MVDC) Systems

III AC RAILWAY POWER SUPPLy SySTEMS

A) Mathematical Models for General Purposes

B) Specific Cases of Use of Simulation Tools and Models

1) Planning/Operation Method Using Optimisation Techniques

2) Power Quality Issues 
3) Solution Proposal Works, Power Electronics and Other Devices

4) Hardware in the Loop Applications

Section IV present the conclusions. As it was mentioned, railway power systems are suffering drastic changes in the present days and this is the trigger of a very dramatic increase of the number of papers and works in this field on study. For this reason, in the present document, the authors will focus in works and tools developed within the last 5 years. Even when we can find very interesting mathematical models of conventional railway power systems published in the past and also many decades ago, the study of such models is beyond the scope of this work.

\section{DC RAILwAY POWER SYSTEMS}

The range of voltages found in DC power systems varies from the $600 \mathrm{~V}$ or $750 \mathrm{~V}$ typical of trams and some subway systems to the $1500 \mathrm{~V}$ and $3000 \mathrm{~V}$ voltages found in heavier and longer-distance train systems. DC electrification has as its main advantage the fact that the use of relatively low voltages reduces insulation problems making these systems, especially those of $600 \mathrm{~V}$ and $750 \mathrm{~V}$ ideal for use in urban environments, with very low powers and speeds, where they share space with other vehicles and pedestrians. In recent years high speed medium voltage DC systems (MVDC) are becoming a reality, and some examples of simulations of these kind of systems are provided at the end of this section.

Normally, DC traction systems are connected to the main AC network through substations composed of transformers and rectifiers that in many cases are not controlled diode-based bridges of 6 or 12 pulses. They do not generate imbalances in the AC network, but they can generate a high harmonic pollution. In addition, this type of installations, although very robust, are not reversible, preventing in many cases to manage in an adequate way the energy regenerated by the trains during the braking. A real scheme of a DC traction substation is represented in Fig. 2 To take advantage of the energy regenerated by the trains, in some cases, controlled inverters in parallel with the rectifiers are installed. In other occasions, energy storage systems can be installed at substation level or on board trains so that the regenerated energy is used directly in the traction network without the need to return it to the main network.

High currents derived from low voltage levels inherently generate a number of drawbacks such as the need to install power substations at a relatively short distances (for example, in the case of $600 \mathrm{~V}$ or $750 \mathrm{~V}$ systems, the distance between substations usually does not exceed $2 \mathrm{~km}$ or $3 \mathrm{~km}$, and may reach $15 \mathrm{~km}$ or $20 \mathrm{~km}$ in $3000 \mathrm{~V}$ systems), network losses are high and train traffic and power, even in $3000 \mathrm{~V}$ systems is limited by the maximum current on the lines.

In this type of systems, a high level of insulation between the ground and the rail is desirable to avoid the current leakage. However, sometimes the impedance between the ground and the rails is not as high as we would wish. These leakage currents, called stray currents, can lead to corrosion problems because the metal could act as anode or cathode and the ground as electrolyte in a corrosion reaction.

Due to all the above-mentioned special features of the DC railway power systems, the efforts of the most recent works were focused on the following topics.

- Development of static mathematical models and solvers. These kinds of models are usually developed for planning and operation purposes. Most of the time they are used in energetic studies or for assess the impact over the whole system of a specific technology. They can include decoupled approaches for simulating the infrastructure and the train separately or integrated approaches that consider both, trains and infrastructure in the same simulation framework.

- Development of dynamic mathematical models and solvers. Usually these models are very detailed and are used for very specific studies with simulation intervals that are not very long. In a vast majority of the occasions, the transient simulations are used to study power quality problems.

- Specific cases of use of different simulation tools and models. This set of works use in many cases mathematical models like the ones described in the previous section but with an specific purpose, trajectory or schedule optimisation, infrastructure optimisation, proposing energy management and control techniques, use the models for hardware in the loop applications or use new power electronic devices like the ones employed in the MVDC railway systems.

The next subsections study and compare the works classified according to the three points above-presented. The subsection related to the last point will describe specific cases of uses of these tools, mostly related to energetic studies or operational modes that improve the efficiency are presented. Usually these works are specific studies that use methodologies developed by other authors or the same authors but applied to specific scenarios in order to study which is the best technological combination or operational mode. These works are generally related with adding energy storage to the system, reversibility to the substations, embedding and managing renewable generation inside the traction systems and coordinating the train schedules or the driving strategy in order to increase the overall efficiency. In most of the cases these techno-economic studies are made off-line and just a few of them are intended to be implemented on-line for real time operation.

\section{A. Development of Static Mathematical Models and Solvers}

Most of the authors working on the development of the mathematical models and solvers with a static approach use the power flow implementation as an analysis tool. They vary the kind of solver and its performance and the definition of the embedded models and their complexity. In recent years, most of the proposed models were focused on determining electric parameters for energetic studies considering the whole traction system. These different works can be divided into decoupled and integrated approaches. 


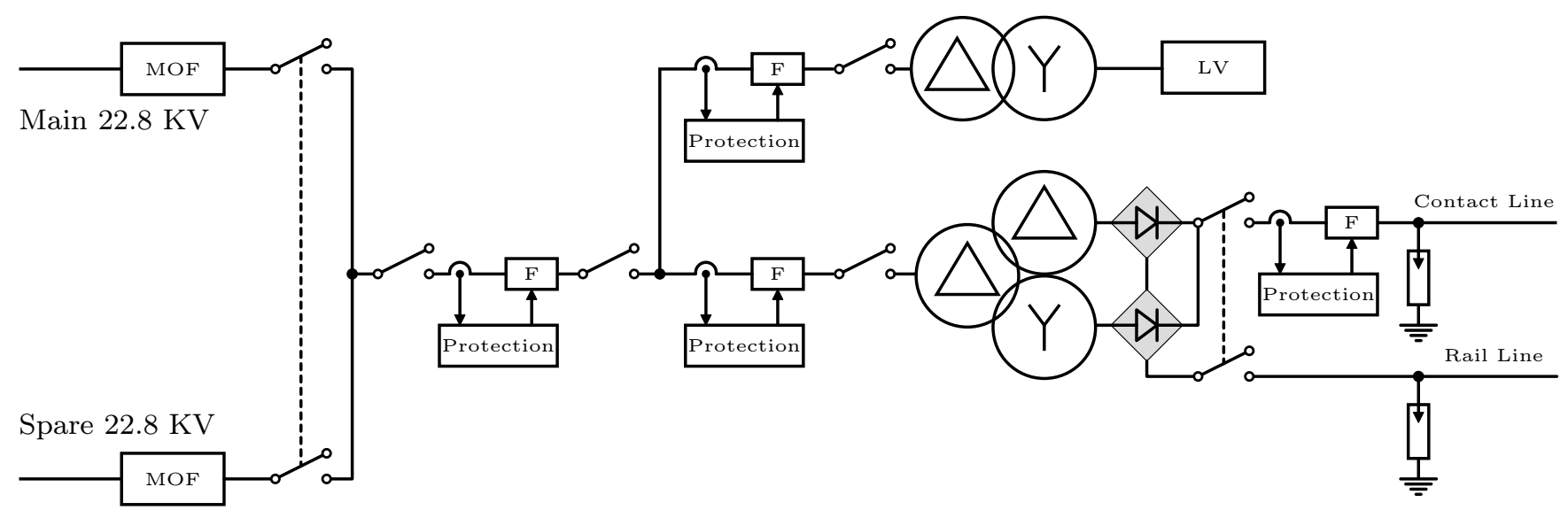

Fig. 2. Real scheme of a DC traction substation.

1) Decoupled Approaches: With the decoupled approach, the kinematical operation of the trains (driving cycles) are supposed to be independent from the supply infrastructure. The train is thus considered as an independent power source. Many authors consider that the network is able to deliver all the power requested by the trains, which is not always true in real life. Indeed, when the train is in traction mode and the voltage is too low, the overcurrent protection can reduce the power requested by the train to protect the electrical equipment. In such cases, the train is not able to accelerate at the specified rate and a delay is the most immediate consequence. The overvoltage protection is activated when the voltage is too high and the train is in braking mode. In such cases, the so called squeeze control or overvoltage protection derives part or the regenerative power to the rheostatic system. In this case, the train schedule is not affected but part of the regenerated power is dissipated, reducing the global efficiency of the railway system. The delays induced by the overcurrent protection cannot be simulated with the decoupled approach, even if it can be detected. However, the reduction in the power demanded or injected by the trains can be calculated by considering the non-smooth and non-derivable characteristics of the overcurrent and the overvoltage protections. Such decoupled approaches can be appropriate to size and design railway infrastructures, study the voltage regulation, or assess innovative technologies such as energy storage devices or reversible substations for specific schedules and operations of the trains. However, it should be avoided to study the train management, the impact of the supply network over the train operations, or the network congestion.

For instance, the work presented in [27] uses a power flow decoupled approach. The authors model both, the trains and the infrastructure, but separately. The trains are modelled as current injections from the infrastructure point of view. The train model determines the power requested and position of the trains at each given instant, which are used as inputs for the infrastructure power flow software. In this paper, the BTS-Sukhumvit line in Bangkok, a 750V system with 10 rectifier substations and a length of $21.6 \mathrm{~km}$, is simulated with a headway between the trains of 5 minutes. The substations are not reversible but the trains are not equipped with regenerative braking. The simplified NewtonRaphson method implemented by the authors achieves the convergence without any remarkable issue. In order to consider the regenerative braking of the trains, [28] proposes a fast algorithm dealing with the non-derivable and characteristics of the protection curves, but the algorithm cannot simulate non-reversible diode-based substations. In [29], the authors introduce a model of non-reversible substations with trains equipped with regenerative braking systems. For this purpose, they implemented a bi-factorisation iterative algorithm. A similar approach can be found in [30], where a robust algorithm is developed for solving $\overrightarrow{\mathrm{DC}}$ railway networks with meshes and non-reversible substations. The non-linearity sources here are basically the non-derivable characteristics of the train protections and the non-reversible substations. Similar approaches can be found in [31], [32]. Another work proposes a power flow method for DC railway systems based in the current injection method that considers the limited receptivity of the network [33]. The authors managed to implement a voltage-current characteristics in the trains, simulating the derivation of part of the regenerated power to the rheostatic system in high voltage scenarios. When all substations are blocked, the trains that are regenerating adopt the proposed voltage-current model. The authors do not consider the overcurrent protection in low voltage scenarios or any other device like energy storage. The tests are performed on a 750V DC system with three substations under different scenarios with $18,36,72$ and 144 trains. The authors do not mention the changes in the train location or behaviour. Analysing the results presented, it seems that only single instants are studied. The results are compared with those presented in [34] and [35].

Innovative technologies such as reversible substations or energy storage systems are critical right now in many railway infrastructures. That is why many authors are investing a lot of effort in the development of accurate models of these devices, and their integration into the decoupled approaches.

For instance, regarding reversible substations, the work in [36] proposes a pseudo-static modelling of the reversible substation to analyse the effect of the different regulation parameters over the used regenerated power and dissipated 


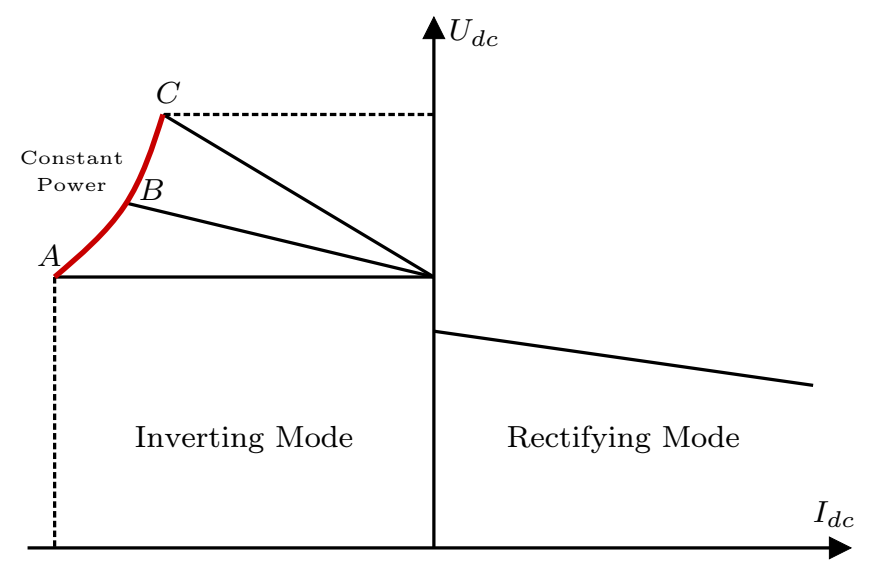

Fig. 3. Working characteristic of a reversible substation

regenerated power among others. A conventional characteristic of a reversible substation formed by a diode rectifier parallel connected to a IGBT converter can be observed in Fig. 3. The right side represent the non-controlled diode rectifier behaviour while the left side represent the reverse conduction through the converter, usually with two zones, constant voltage and constant power. The power flow simulator is fed with the power profiles of the trains. The interaction of the train and the power system is considered by means of the squeeze control implementation. The reversible substation works first in constant voltage mode and, when the maximum power is reached, in constant power mode increasing the voltage. The authors study how the start working voltage, the control of the virtual resistance and the size of the inverters affect to the efficiency of the system, but also to the cost. Further research is focused on the influence of the headway, since all the studies of the mentioned paper consider a fixed headway. Steady state models of reversible substations, but also storage systems, are presented in [37] to be included in a power flow simulation tool of DC railway systems. Other works such as the one presented in [38] study the potential electricity cost reduction allowed by the train to grid technology based on reversible substations. A similar approach is presented in [39], where the substation in forward mode is operated using the two segments, constant voltage and constant power. By means of the control, the authors can emulate a virtual impedance in both directions forward and reverse. In addition, this work combines a transient and static solver in the same platform. The steady state solver is used for the energetic studies and for initialise the transient solver. The transient solver can provide the effect of the control parameters over the system and study power quality issues. The work presented in [40], proposes a new control for reversible substations in order to optimize the power sharing among the different substations. The reversible substations are modeled by means of a non-controlled rectifier in parallel with a converter which is quite conventional, but in this case, the authors allow the converter to operate also as a rectifier controlling the voltage of the substations when it is working in forward mode.

Regarding energy storage elements, the works in [41] and
[42] present mathematical models of DC railway systems considering on-board and off-board storage systems, but also reversible substations. The mathematical models of the different devices are explained and the performance of the system with different configurations are compared. The losses in the DC system and at substation level in addition with the power dissipated into the rheostatic system and other electrical parameters are analyzed to obtain the overall efficiency of the feeding system for each configuration. A similar approach can be found in [43] for an on-board hybrid energy storage systems. In [44] the authors propose a formulation to evaluate the efficiency increment when adding energy storage at substation level, considering a hybrid AC/DC power flow. The non-reversibility of the diode based substations and the train protection curves (overcurrent and overvoltage) are not simulated. The non reversibility behaviour is not necessary to be modeled because potential reverse power flows are eventually absorbed by the energy storage systems. The methodology is applied to a line of $3 \mathrm{kV}$ between Firenze and Livorno of around $100 \mathrm{~km}$. The authors provide the details for replicate the train and network models. In the model presented in [45], the authors use a modified nodal analysis for solving the power flow problem. The substations are modeled as reversible devices, but reverse power flows (from DC traction systems to the AC network) are avoided through the use of a wayside energy storage devices. More examples of static simulators of DC traction networks with wayside energy storage can be observed in [18], [46]. In both cases, a mathematical model is proposed and implemented to study a specific scenario and evaluate the potential regenerative energy, voltage stabilization and reduction of peak power demand that can be obtained with this technology.

Very specific models can also be developed to study particular parts of the system. For instance, [47] proposes a mathematical model of the return circuit considering the grounding system of the DC railway specially conceived to study the stray currents. Such a detailed model is not very common in the last years since most of the authors are focusing in simplified models able to simulate extensive transportation networks. Another exception is presented in [48], where a test bench is developed for emulating in a very accurate way the stray currents in grounded DC railway systems. Power electronics circuits are used as variable resistors to simulate the train motion. Buck and boost converters are used to emulate high and low ground impedance of the rails.

2) Integrated Approaches: The integrated approaches model the electric network together with the trains and adapt the kinematical operations of the trains according to the supply network. In opposite with the decoupled approaches, the integrated approaches can be used to study the train management, the impact of the supply network on the train operations, and the network congestion. Only a few works use such approaches. The idea proposed in [49] is related to the simultaneous simulation of trains and system using static models. In this case a multi-scale framework is proposed to connect different systems (network and trains) with different time constants. The novelty is the use of the heterogeneous multi-scale methodology. The whole system is divided in 


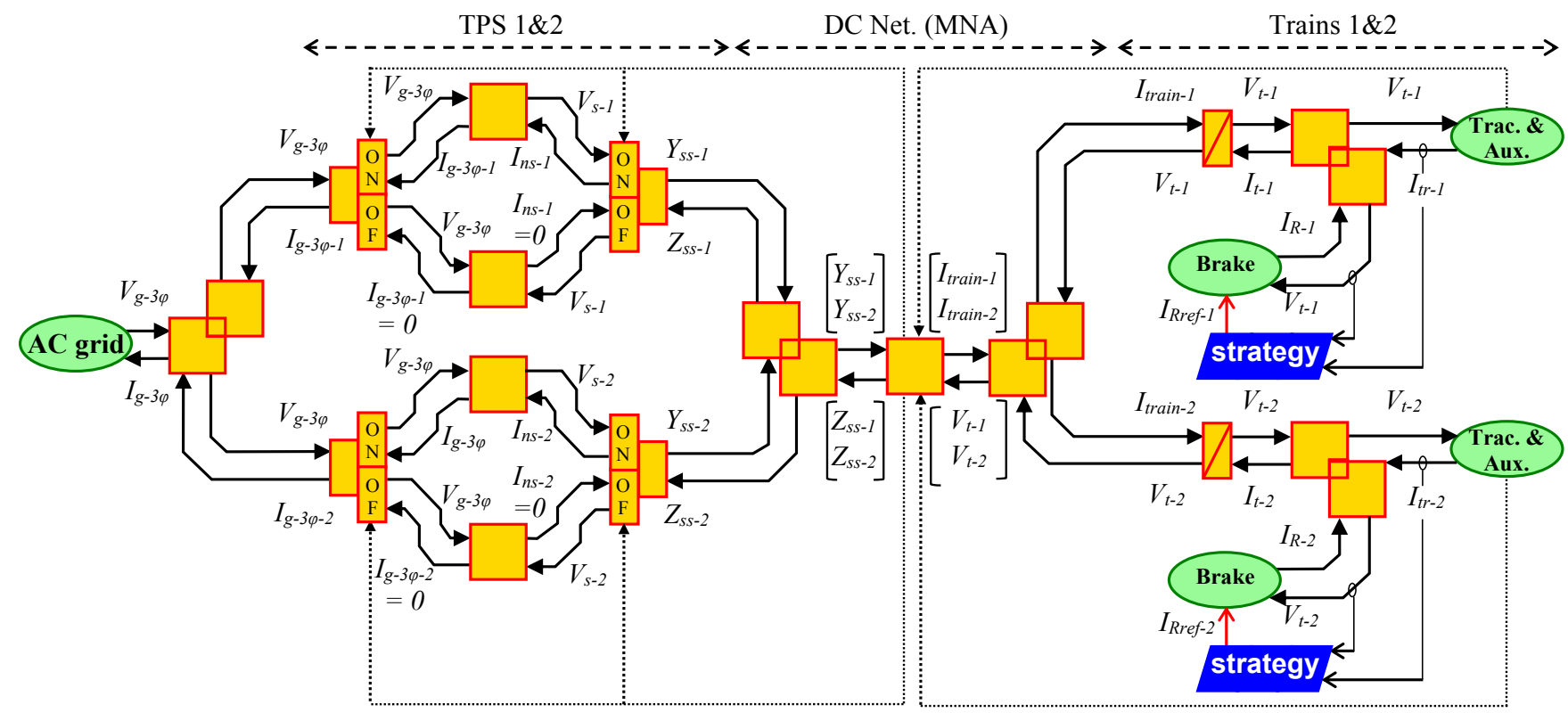

Fig. 4. EMR representation of a DC traction system plus the trains

a so called macroscopic model containing the grid and the train electrical equipment, and the microscopic model containing the trains electro-mechanical model. Both models are coupled using a reconstruction operator containing the mechanical power calculations and a data estimator including the basic train control. Another example of integrated model can be found in [50] but it is based on a dynamic model, which is described in the next sub-section. This tool is able to evaluate the impact of the DC network behavior over the trains operations considering the overcurrent and overvoltage protections. The tool is used to evaluate the different possibilities to extend a subway line with a denser traffic, evaluating the congestion in the DC network, the impact on the speed profiles and the trains performance.

\section{B. Development of Dynamic Mathematical Models and Solvers}

Regarding dynamic simulations, most of the works present detailed models of simple feeding infrastructures with or without trains or very detailed models of specific parts of the systems like substations or energy storage devices.

The authors in [51] propose a small-signal model in which they consider the trains, the substations, but also PV systems. The authors claim that stability issues could arise in the network due to the effect of the distributed generation resources. They consider VSC-based reversible substations and they model the control of the substations, PV plants and trains. The authors propose a stability index and study the effect of the different devices and their control parameters over the stability of the system. The use of a virtual impedance is considered for controlling both, the PV plants and the VSCbased substations, to stabilize the system.

In [52], a dynamic simulation tool that consider the train model, plus the non reversible substation model together with different kind of energy storage technologies and controls is presented. The model is implemented in Matlab-Simulink. It is used to study the impact over the network of the energy storage technologies and the authors state that it is developed for a multi-train scenario. The tests are developed for a section of the line 7 of New York City Transit System, containing 3 substations and 4 passenger stations. The tests include several speed profiles but just one train. The results are validated with real measurements sampled at $5 \mathrm{kHz}$. No data is provided about the simulation speed or the influence of the number of trains and substations or sampling period over the simulation time.

The authors in [53] propose the use of multiport converters to add energy storage at substation level in a $3 \mathrm{kV}$ DC line. Real data form an Italian regional line of $24 \mathrm{~km}$ from Saronno to Como Lake is used. The multiport devices are connected in parallel with the conventional diode rectifier and it allows to control the power flow from the $\mathrm{DC}$ to the $\mathrm{AC}$ system and to the energy storage device. Simulations are carried out using Matlab-Simulink software like in the previous case.

Some authors used the Energetic Macroscopic Representation (EMR) to develop coherent and physical models of different infrastructures, vehicles and devices. Such an approach is used to better highlight the energy interactions among the different subsystems while respecting the integral causality. An example of an EMR representation of a DC system composed by two substations and two trains plus the feeding wires is represented in Fig. 4 For instance, the work in [54] is focused on the model of a traction power substation considering the non-linearity caused by the switching of the devices. An extremely accurate EMR-based model is obtained but it is quite complex and slow, even when only one substation and one train are simulated. The authors therefore propose simplifications of this model to achieve an accurate static averaged model improving the speed of the solver. The developed models are validated based on experimental measurements on Lille metro line in France. 
The same authors propose in [50] a dynamical model of a DC traction network with an integrated approach. It considers trains plus electrical infrastructure, including the overcurrent and overvoltage protections, the grid and the diode-based non-reversible substations. The model is really accurate and it is able to provide solutions even when all substations are blocked at the same time. The validated model is used to compare three different scenarios for a subway line extension. The model is implemented and solved using Matlab-Simulink.

A different use of the dynamic simulation applied to DC railways is described in [55]. Two methodologies are presented to evaluate the stray currents in DC railways. Different kind of soils and grounding systems are studied. The first methodology is based in a finite element model (FEM) and the other one based in a Matlab-Simulink model.

\section{Specific Cases of Use of Different Simulation Tools and Models}

The new technologies and operations must be assessed in terms of cost, efficiency and energy savings before their real implementation in the systems. It is the main reason why many simulation tools are developed nowadays as presented in the two previous subsections. This third subsection thus describes different works that use such tools to assess these impacts and improve the operations and the energy management within DC traction systems. While in the previous works, the mathematical models where somehow described. Most of the works in this subsection just mention the mathematical apparatus and they are mostly focused on the case of study.

The papers that propose off-line studies for planning and design purposes as well as papers that propose energy management tools for real time applications will be considered. Most of these works present figures that endorse the management or technological proposals. We must point out that most of the times, it is very difficult to compare different proposals. In this regard, the work presented in [56] presents a set of key performance indicators in four different categories 1) Power Supply Network 2) Rolling Stock 3) Depots and 4) Rest of infrastructure like station lighting, escalators or tunnel ventilation. The description of these indices provided by the authors can be observed in Table I]

A standardization effort, to get a set of general indices used by all researchers to evaluate their solutions, would be critical in the next years in order to compare accurately different technologies, but the ones proposed in the above mentioned manuscript are an excellent starting point.

Within the works that make energetic studies we can find a wide range of different approaches for planning and operation purposes. For instance, we can find trajectory and driving optimization techniques, schedule optimization, optimal placing and sizing for specific devices or the whole infrastructure, specific management techniques of a single device or the whole network, operation procedures for real time operation.

Below, the works are classified under 3 subsections: trajectory and schedule optimisation, infrastructure optimisation, and energy management and control. In addition, two subsections describing works dealing specifically with hardware in the loop (HIL) applications and MVDC railways are presented at the end of this section.

1) Trajectory and Schedule Optimisation: Among those papers dedicated to train trajectory and schedule optimisation, we can find different approaches, from very simple to very sophisticated methodologies. In [57] the authors propose an optimisation approach to obtain the best train trajectory. It is tested in a $13.77 \mathrm{~km}$ path with 15 stations connecting Edinburgh with its Airport for a train with a maximum traction power of $907 \mathrm{~kW}$ and a maximum speed of $70 \mathrm{~km} / \mathrm{h}$. The results are used to train drivers to drive in a more efficient way. In this case, there is no interaction between the train and the feeding system so the effect of other trains and the congestion of the system is not considered. Similar works are presented in [58] and [59].

A more complex approach with several trains is presented in [60]. This paper proposes an optimization method to maximize the use of the regenerative braking energy with nearby trains or storage devices. No power flow algorithm is proposed. The method only considers the energetic values and the schedule and runs an optimisation. It provides as a test bench a complex scenario with 14 stations and 8 trains in a line of $22.73 \mathrm{~km}$ connecting Songjiazhuang station to Yizhuang station in Beijing Metro Yizhuang Line. The method achieves a significant improvement with an optimal solution that can use more than $93 \%$ of the regenerated energy with an energy use reduction higher than $30 \%$. In this kind of method, no electrical variables beyond the energy of the devices is analysed.

A similar approach is used in [61] for optimising the schedules of the trains considering factors like train headway and dwelling times. Basically, a meta-heuristic optimization synchronizes accelerations and braking of nearby trains, increases the re-utilisation of the regenerated energy and avoids as much as possible the rheostatic braking. This optimization procedure is applied in a real Beijing metro line. Some possible "noise" is also considered in the timetable caused by unexpected delays and even in those situations the improvement in energy efficiency is higher than $18 \%$.

Another example of cooperative coordination of the schedules is proposed in [62] where the authors calculate the optimal train departures to improve the efficiency and make use of the energy regenerated by other trains. The methodology is applied to the Yizhuang Line in Beijing Subway reducing the consumption by $11.34 \%$. Based on the same idea to improve the efficiency through the schedule and headways coordination, the work in [29] uses a power flow simulation to find off-line the best combinations by testing several scenarios. A maximum of $27 \%$ energy saving is obtained with the best combination. In this work, the traction network is solved using a bi-factorisation iterative algorithm. Another similar case is the work in [63] where the speed trajectory is optimized to reduce the net energy in the system.

2) Infrastructure Optimisation: Previous works were intended to be used for planning purposes but specifically for schedule improvement. None of them considered different kind of technologies to study the impact over the system. 
TABLE I

PERFORMANCE INDICATORS ACCORDING TO [56]

\begin{tabular}{|c|c|c|c|}
\hline Code & Name & Description & $\begin{array}{l}\text { Subsystem } \\
\text { affected }\end{array}$ \\
\hline$P I_{01}$ & $\begin{array}{l}\text { Electrical substation } \\
\text { efficiency }\end{array}$ & $\begin{array}{l}\text { Total energy flow at the exit of a particular substation over the total energy flow at the exit of } \\
\text { a particular substation over the total energy flow at its entrance for a given load cycle }\end{array}$ & Power supply \\
\hline$P I_{02}$ & $\begin{array}{l}\text { Power distribution } \\
\text { line efficiency }\end{array}$ & $\begin{array}{l}\text { Total energy flow at the entrance of the rolling stock over the total energy flow at the exit of } \\
\text { the substations for a given section of line under a given load cycle }\end{array}$ & Power supply \\
\hline$P I_{03}$ & $\begin{array}{l}\text { In-service traction } \\
\text { energy consumption }\end{array}$ & Traction energy consumption for a given vehicle per passenger-km for a given duty cycle & Rolling stock \\
\hline$P I_{04}$ & $\begin{array}{l}\text { In-service auxiliaries' } \\
\text { energy consumption }\end{array}$ & Auxiliaries' energy consumption for a given vehicle per passenger-km for a given duty cycle & Rolling stock \\
\hline$P I_{05}$ & $\begin{array}{l}\text { Braking energy } \\
\text { recovery }\end{array}$ & $\begin{array}{l}\text { Percentage of a single vehicle's gross traction power consumption (measured at pantograph level) } \\
\text { that is regenerated during braking for a given duty cycle }\end{array}$ & Rolling stock \\
\hline$P I_{06}$ & $\begin{array}{l}\text { Braking energy } \\
\text { recovery efficiency }\end{array}$ & $\begin{array}{l}\text { Percentage of the maximum percentage of regenerative braking energy recovery that is actually } \\
\text { regenerated in a single vehicle during a given duty cycle }\end{array}$ & Rolling stock \\
\hline$P I_{07}$ & $\begin{array}{l}\text { Depot building's } \\
\text { energy consumption }\end{array}$ & Energy use in a single depot building per unit of net floor area for a predefined operational cycle & Depots \\
\hline$P I_{08}$ & $\begin{array}{l}\text { Parked vehicle's } \\
\text { energy consumption }\end{array}$ & Energy consumption of a single parked vehicle per passenger capacity unit for a given duty cycle & Depots \\
\hline$P I_{09}$ & $\begin{array}{l}\text { Station HVAC } \\
\text { energy consumption }\end{array}$ & $\begin{array}{l}\text { Energy consumed by HVAC systems in a single station per square meter, given a predefined } \\
\text { operational cycle }\end{array}$ & Infrastructure \\
\hline$P I_{10}$ & $\begin{array}{l}\text { Station lighting \& info } \\
\text { systems energy }\end{array}$ & $\begin{array}{l}\text { Energy used for lighting and information purposes within and individual station per square meter } \\
\text { under a predefined operational cycle }\end{array}$ & Infrastructure \\
\hline$P I_{11}$ & $\begin{array}{l}\text { Station passenger flow- } \\
\text { related energy use }\end{array}$ & $\begin{array}{l}\text { Specific energy consumption of a single passenger flow-related system for a given operational } \\
\text { regime; this comprises lifts, escalators and other passenger conveyor systems }\end{array}$ & Infrastructure \\
\hline$P I_{12}$ & $\begin{array}{l}\text { Tunnel ventilation } \\
\text { energy consumption }\end{array}$ & $\begin{array}{l}\text { Energy used by ventilation systems in a specific underground section per } m^{3} \text { of tunnel volume } \\
\text { under predefined operational conditions }\end{array}$ & Infrastructure \\
\hline
\end{tabular}

Papers that study different kind of technologies, their impact in the network, their optimal sitting and sizing and the best set-up for the different technologies use optimization tools very frequently. One of the main issue with the optimization procedures is the high computational burden. For this reason the authors in [64] propose a compression system for simplify the amount of data provided by each scenario in an optimisation process. Usually, for optimising, authors need to study different scenarios. If the sampling frequency is very high (1 second for instance), thus the amount of data provided by each scenario is huge. However, down-sampling the data can generate significant errors. With the proposed compression system, the number of samples that identify each scenario are drastically reduced so the optimisation time can be improved in an $80 \%$ with an error that do not exceed $5 \%$.

The work in [65] proposes a method for optimising the size and location of a reversible substations. The authors use the conventional reversible substation configuration connecting one non-controlled diode bridge in parallel with a controlled converter. The control implemented for the reversible characteristic considers constant voltage control. This paper uses a decoupled approach but considers the train models and the network in the same mathematical framework. The trains are modeled considering the overvoltage protection so the results are quite realistic. Since no overcurrent protection is implemented the authors cannot simulate delays. The substations and trains are modeled respectively as voltage sources and current sources. The substations are blocked during the iterative process when they are non-reversible if a reverse current is detected. The authors test the system with a $97.1 \mathrm{~km}-$ long railway line between EastWarsaw Station and Siedlce Station in Poland, simulating an entire day considering a total of 214 trains of 3 different types. Other examples of optimal placing and sizing are for instance the papers [66] and [67]. In the first one the authors propose a method for obtaining the optimal placement, size and control parameters of an off-board energy storage system battery-based in the simulation of a real $3 \mathrm{kV}$ DC Italian railway system connecting Magliana and Fiumicino. The authors obtain a reduction in the annual cost of energy higher than $13 \%$. They also compare in terms of cost, the installation of the off-board energy storage system with the deployment of a new conventional substation and the results shows that in some cases the storage alternative is also cheaper. The second paper is very similar. The definition of the so called current distribution factor (CFD) introduced by the authors in [68] allow us to determine in a quite simple way the target amount of regenerative energy that can be reused in a specific infrastructure.

In [70], the objective is to determine the impact of the installation of the reversible substations and the accumulation devices over the efficiency of the system. A traffic simulation scenario is thus coupled with a power flow solver, but no detail about the power flow solver is given. The study is focused on the traffic simulator to generate complex and realistic traffic scenarios, with different headways, time shifts at terminal stations, non-constant dwell times and different speed profiles. They actuate over the infrastructure but also over the traffic and the schedules to obtain the best configuration. In [42], a set of rules are proposed to manage the control of the offboard energy storage system considering that the trains are equipped with regenerative braking. The authors maximize the usage of the energy storage system by actuating over the charging and discharging voltage thresholds. They consider the voltage at which the rheostatic braking is activated and they adjust the charging voltage of the energy storage device to be lower, if possible, to avoid the use of the rheostatic braking. A simulation is achieved in a very simple system using two 


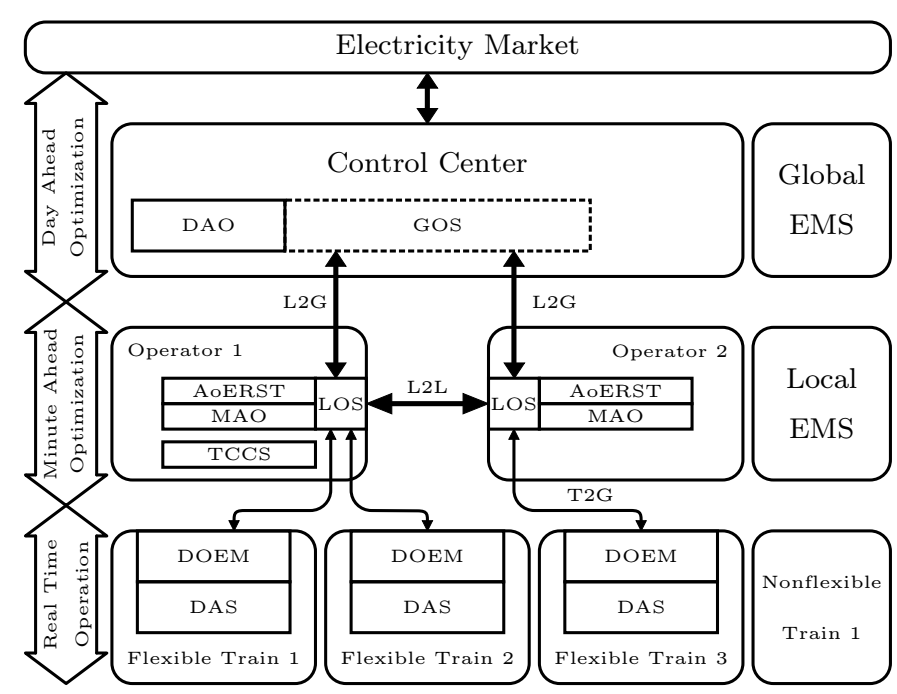

Fig. 5. Representation of different interactions of the Railway Energy Management System Tool (R-EMS) presented in [69]. As it can be observed all the agents are involved, the electricity market, the control center the real time operators and the trains. It combines day ahead optimization (DAO) made by the global optimization system (GOS) with minute ahead optimization (MAO) made by the local optimization system (LOS) and dynamic on board energy management (DOEM) made at train level considering that the trains are equipped with driver advisory systems (DAS). Many different models are required in order to run all the optimizations like for instance the Adapted online exisitng railway simulation tool (AoERST) or the traffic control center simulator (TCCS). Of course, communications are of extrem importance like the LOS to GOS (L2G) communication, the LOS to LOS (L2L) communication and the train to ground (T2G) communication.

trains with the data obtained from a real infrastructure (Beijing Batong Subway line). An increase in the efficiency of $13.5 \%$ is obtained with the proposed strategy. This is a clear case in which the authors optimise the infrastructure set-up without varying the schedules or the technologies added to the system. A similar approach is presented in [71] but in this case the accumulation systems are installed on-board. The authors use a multi-train simulator to determine the state of charge of the on-board battery and the control of the charge/discharge process in all points of the path in order to increase the energy efficiency of the whole system. Similar works, but using onboard flywheels [45] or hybrid battery/ultracaps [72] as well as wayside energy storage systems [73] can be found in the literature. In [74], ultracapcitors are used but in this case of DC stabilization purposes.

Another example in [75] proposes to use electric vehicles in charging mode as energy storage systems for urban DC railway systems. The braking energy that is dissipated in the rheostatic brake in conventional operation could be used to charge EV instead. This paper estimates that between 685 and $1000 \mathrm{EVs}$ could be charged every day using the wasted braking energy for the two studied metro lines, respectively in Spain and Italy.

3) Energy Management and Control: Just a few works are dedicated to the real time operation of the systems. Among them, most of the works propose and simulate operation strategies and just a few realistic frameworks or implementations. It is remarkable the operational framework proposed at H2020 MERLIN project described in the papers [76] and [77]. In the project, advanced techniques coming from the smart grid field were applied to the railway energy management topic. The proposed control is hybrid, centralised/distributed, and basically optimises the energy consumption, reduces the power peaks and optimizes the costs of operation by coordinating the trains, on-board and wayside accumulators. Some of the control parameters are defined according to local variables while other ones are set using a centralised approach. The centralised system is executed in a day-ahead scenario while the decentralised energy management operates in intervals of a few minutes ahead. The system considers also the trains speed profiles suggesting changes on them. Both problems, centralised and decentralised are stated as optimization problems. The project covers also all possible layers in this management system describing the component layer but also the information layer and the communication layer. The proposed system was tested and validated using the $3 \mathrm{kV}$ DC railway connecting the cities of Malaga and Fuengirola in the south of Spain.

Similar approaches combining hybrid centralized/distributed operation philosophies can be found in [78] and [69]. The first paper proposes a cooperative methodology to improve the overall efficiency of the system. It uses a communication based train control (CBTC) combined with distributed optimization procedures together with a centralised train control (CTC). It assumes that all trains are equipped with automatic train operation systems (ATO) or the trains are equiped with some typo of driver advisory system. The authors claims that this procedure must be done in real time, since other procedures that are focused on optimizing a single train driving do not consider the interaction between the trains. Also, the procedures that optimise the energy based on adjusting the schedule do not take into account that most of the times there are small delays that affect very much to the synchronization of the traction and braking of nearby trains. The second paper present two software suites, one to be used off-line that is commonly applied for the next day optimisation and another one with a shorter time horizon that is used for on-line operation purposes. It considers the electrical infrastructure as well as the trains. The idea is to obtain an accurate representation of the best configuration for the next 15 minutes-time slot and coordinate the smart substations, the energy storage devices, the trains and the distributed energy resources to increase the global efficiency of the system. The general structure of the so called Railway energy management system (R-EMS) suite is presented in Fig. 5

The rest of the works for real-time operations present much more simplified scenarios. For instance, in [79], the authors propose to adjust in real time the speed profile of the trains that are close to other trains in regenerative braking mode. This is a cooperative operation principle designed for automatic train operation systems. In [80] the authors study how the use of a wayside energy storage can help to control the catenary voltage. The studies are made in the Italian Tramway Network of the city of Naples. They propose a control of the wayside storage to keep the voltage within the margins. The whole system is implemented and validated in a very sophisticated laboratory workbench, so the authors validate that the procedure can be implemented for real-time 
operation purposes. The authors of [81] test the benefits over the power quality and the efficiency of the system of installing reversible substations or wayside accumulation systems for the Thessaloniki metro line of $6.6 \mathrm{~km}$. A headway between trains of $300 \mathrm{~s}$ is considered in this study. Both cases are modelled as an optimisation problem considering that the implementation of a real time centralised controller is possible. In the case of the wayside accumulation system the authors uses a multiperiod optimisation approach. In both cases, the optimisation strategy tries to regulate the train voltages to be close to the reference voltage. Centralised control systems like the one proposed here are not common in real life applications since they need to use the real time electrical signals in all nodes of the network (including trains).

A coordination strategy based on a multi-agent system is also presented in [82] to integrate renewable energy in the DC traction grid together with energy storage. The paper is very simple from the electrical point of view, since it considers the whole network as a capacitor and all the trains, PV panels, wind turbines and wayside energy storage are connected to that capacitor. The work in [83] proposes to optimize the use of a regenerative braking of the trains in the stations with energy storage and PV generation. The authors study factors like the stochastic nature of the PV generation, the initial state of charge of the energy storage and the occupancy degree of the trains. The consumption in the DC traction network due to trains is obtained using RAILSIM commercial simulator. The methodology is applied to a specific station of the Istanbul metro line of $19.7 \mathrm{~km}$. The escalators, elevators, ventilation, lighting, heating and air conditioning system are also considered in the station. The optimal management is calculated by means of a mixed-integer programming (MILP) problem solved using the GAMS optimization software.

Finally, other works propose energy management in very specific devices inside the network. For instance, [84] proposes a control philosophy to manage the hybrid supply of a catenary free train. Even if the train is not connected to the catenary, it is considered a DC system since all the components, fuel cell, battery and ultracaps are similar to those that can be found in a DC railway system. The control is based on an adaptive droop that optimises the hydrogen consumption while guaranties safe operation conditions in all devices.

4) Hardware in the Loop Applications: In the last years, the number of authors that use hardware in the loop (HIL) tools applied to the railway simulations increased drastically. HIL simulation still require expensive machines but prices during the last decade drooped substantially making them affordable for many applications. We can find works focused on both DC and AC traction systems. Regarding DC traction systems, three important works must be mentioned. In [85], a detailed model of the traction system of a tram, considering an independent control for each rotating wheel is presented. It considers the regenerative braking of the tram but the regenerated power has to be recirculated to a load model since the substations are non-reversible. All of these models are useful to tune the controls of the real systems but they are too complex to simulate large multi-train scenarios. Another very accurate and detailed model is presented in [86]. The work propose a model of the railway network as well as the vehicles and their controls. The authors conclude that the train capacitor is a critical device in the simulation results. They propose a monotrain simulation that is validated using a real infrastructure. After the validation the authors extended the model for a two train and two substations. They claim that this is a first step to develop a HIL tool for a multi-train scenario. In [87], HIL software is used to model superconducting devices for fault limitation application in DC railway systems.

5) Medium Voltage DC (MVDC) Systems: The papers described here refer to a kind of railway system that can not be classified as a conventional DC systems because the voltage level is higher and the feeding characteristics of the network are totally different when compared to the conventional DC feeding system. These kind of railways are the so called MVDC railway systems. This kind of network is not conventional at all and the number of works and simulations related to this topic is very limited. In [88] the authors propose the use of multilevel converters in order to achieve voltages that allow the operation of high speed trains. With this approach the controllability of the network is increased, removing the dead zones and coordinating the power flow and voltages of the substations. The authors propose a control based in an improved droop that can adjust the slope and the position of the droop characteristic dynamically. The same idea was proposed for many different applications in DC microgrids but here it is proposed for railways. The authors developed a MATALB/Simulink model with a detailed control. The system is tested in a threesubstations line with two trains, and the authors consider that the trains are static at two points placed at $40 \mathrm{~km}$ and $60 \mathrm{~km}$ respectively from the starting point of the line. The controls are tested for simulation intervals up to one second and a small prototype is proposed, but the system is not tested with a complex traffic scenario.

The work in [89] proposes a methodology to estimate the equivalent DC system of a specific AC traction network. For that purpose, a power flow studies and thermal calculations are performed to obtain the voltage level equivalent in terms of train performance, temperature of the wires and rail voltages. The methodology is used to obtain the DC equivalent system of an SNCF high-speed trains line, from Paris to Strasbourg, supplied in $25 \mathrm{kV}$ AC. In addition, different typologies and controls are proposed for future traction converters and several dynamical calculations are provided. The authors conclude that considering the energy exchange between trains, not all substations should be reversible. Another conclusion is that above $7.5 \mathrm{kV}$, the distance between DC substations could be comparable with $25 \mathrm{kV}$ AC systems. A $9 \mathrm{kV}$ DC equivalent system is used in this specific case. The most interesting part of this study is the development of the data presented in Fig. 6 which presents the maximum substation spacing versus the catenary cross section for different MVDC levels.

\section{AC RAILWAY POWER Systems}

The use of AC systems allows the use of higher voltages ranging from $15 \mathrm{kV}$ to $25 \mathrm{kV}$, reducing line losses and increasing the power per substation as well as the separation 


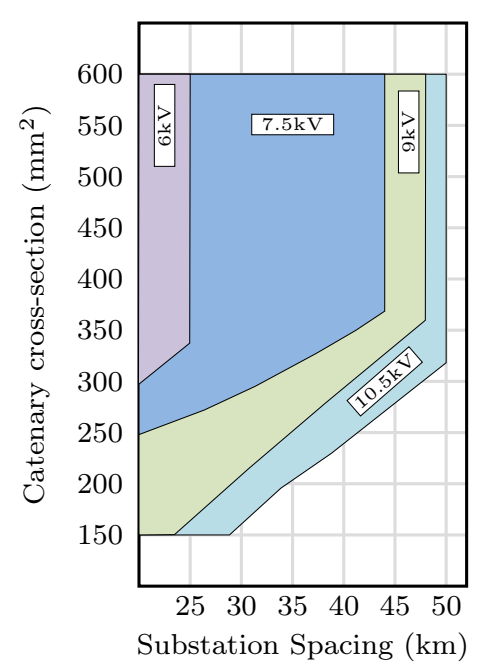

a) High-speed transport

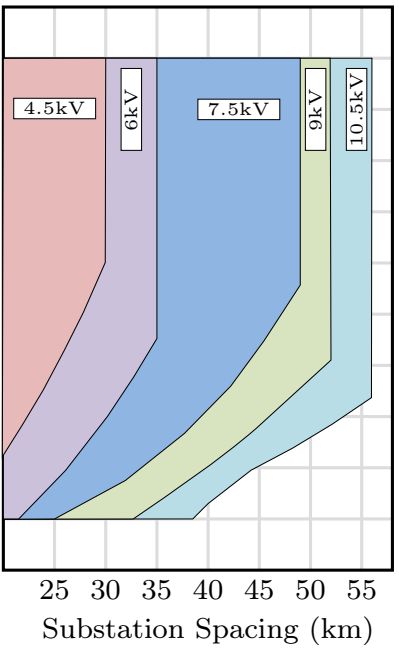

b) Suburban transport

Fig. 6. Substation spacing in MVDC systems versus catenary cross section for different voltage levels [89].

between them as a general rule. A disadvantage of this type of systems is the increase in cost due to insulation requirements. There are many types of AC electrification that deserve to be studied individually due to their peculiar characteristics.

Among the most distinctive features is the feeding frequency, there are in this sense two large groups of systems, those that use the frequency of the main network (usually $50 \mathrm{~Hz}$ or $60 \mathrm{~Hz}$ ) or those that use a reduced frequency, usually about a third of the main grid frequency $(16 \mathrm{~Hz}$ and $2 / 3)$, although there is electrified lines at $25 \mathrm{~Hz}$. The most typical voltage in low frequency lines is $15 \mathrm{kV}$. In the case of lines that use main grid frequency, they usually use voltages of $25 \mathrm{kV}$. On the other hand, the distribution scheme in AC railways can be single level or double level (bi-level). In both cases the train receives the single voltage of $15 \mathrm{kV}$ or $25 \mathrm{kV}$, but in the case of bi-level systems the distribution in a large part of the traction network is done at double voltage, i.e. $30 \mathrm{kV}$ or $50 \mathrm{kV}$. In Fig. 7 the basic structure of conventional single level and bi-level AC railway feeding systems are represented.

In recent years, the adoption of many techniques already applied in AC conventional smart grids to the AC railway feeding systems [90] triggered the modernisation of $\mathrm{AC}$ railway feeding systems. This is the main cause of the drastic increase of research works in this field. As in the DC case, the works can be divided in static and dynamic simulators, and those that propose specific operation techniques. However, in this case, another division is adopted to group into different topics and subsections the different research works.

- Mathematical models for general purposes. We can find a set of papers which propose static models, mainly for power flow analysis, and dynamic models of the railway traction network or some specific device, but without a specific purpose.

- Specific cases of use of different simulation tools and models. This set of works use in many cases mathematical models like the ones described in the

previous subsection but with a specific purpose, like planning or operation of the network, solving power quality issues, developing hardware in the loop simulations, proposing solutions with new devices to the networks or simulating very specific scenarios.

In the next subsections the different works are classified according to the two points aboce-presented.

\section{A. Mathematical Models for General Purposes}

Most of the simulation frameworks for general purposes are focused on static models for power flow studies. An example is proposed in [91], where a simplified current injection method is used to simulate a $2 \times 25 \mathrm{kV}$ system. A decoupled approach is considered but the interaction between the trains and the network is simulated by means of the over-current and overvoltage protection implementation. The authors use a fixed power factor for the trains and a simplified model for the substations so it is not suitable for studying the effect of the traction network over the main grid in terms of unbalances. However it is able to solve long simulation periods with a large number of substations, sections and trains.

The work in [92] proposes a multi-train simulator using a multi-conductor simulation approach rather than a lumped analysis. The paper is focused on the feeding infrastructure model, proposing a very flexible and complete set of models that simulate different configurations (single or bi-level AC voltage). It can consider many kind of devices like autotransformers, boosting transformers and quite detailed grounding models. The trains are modelled as positive or negative admittances. The problem of such a model is that the admittance value should be determined in an iterative way to find the proper admittance for representing a specific consumption or generation and to match with the traction characteristic. It thus leads to complex simulations. A power flow model for $2 \times 25 \mathrm{kV}$ systems, which is solved using Newton-Raphson algorithm, is proposed in [93]. All the elements of the jacobian matrix are obtained analytically, and a Norton equivalent of the substations is deduced. This methodology is applied to the high speed line from Nakhon Ratchasima to Nong Khai of more than $300 \mathrm{~km}$. It is composed of 38 trains (19 for each direction) with a headway of 15 minutes. The trains are modeled as current sources.

Among the few multipurpose dynamic simulations, the one proposed in [94] can be remarked. It proposes a detailed model of all the components of the AC traction system of a train, and considers the propulsion as well as the regenerative working modes. The different devices are implemented together with their control and dynamic simulations carried out with MatlabSimulink are provided. A simple model of the network and a substations is also considered, but it is not intended to be a multi-train simulation tool.

\section{B. Specific Cases of Use of Simulation Tools and Models}

This subsection describes works that use simulation tools and models for specific purposes. Below these works are classified under 4 types of purposes: planning/operation methods using optimisation techniques, power quality issues, 

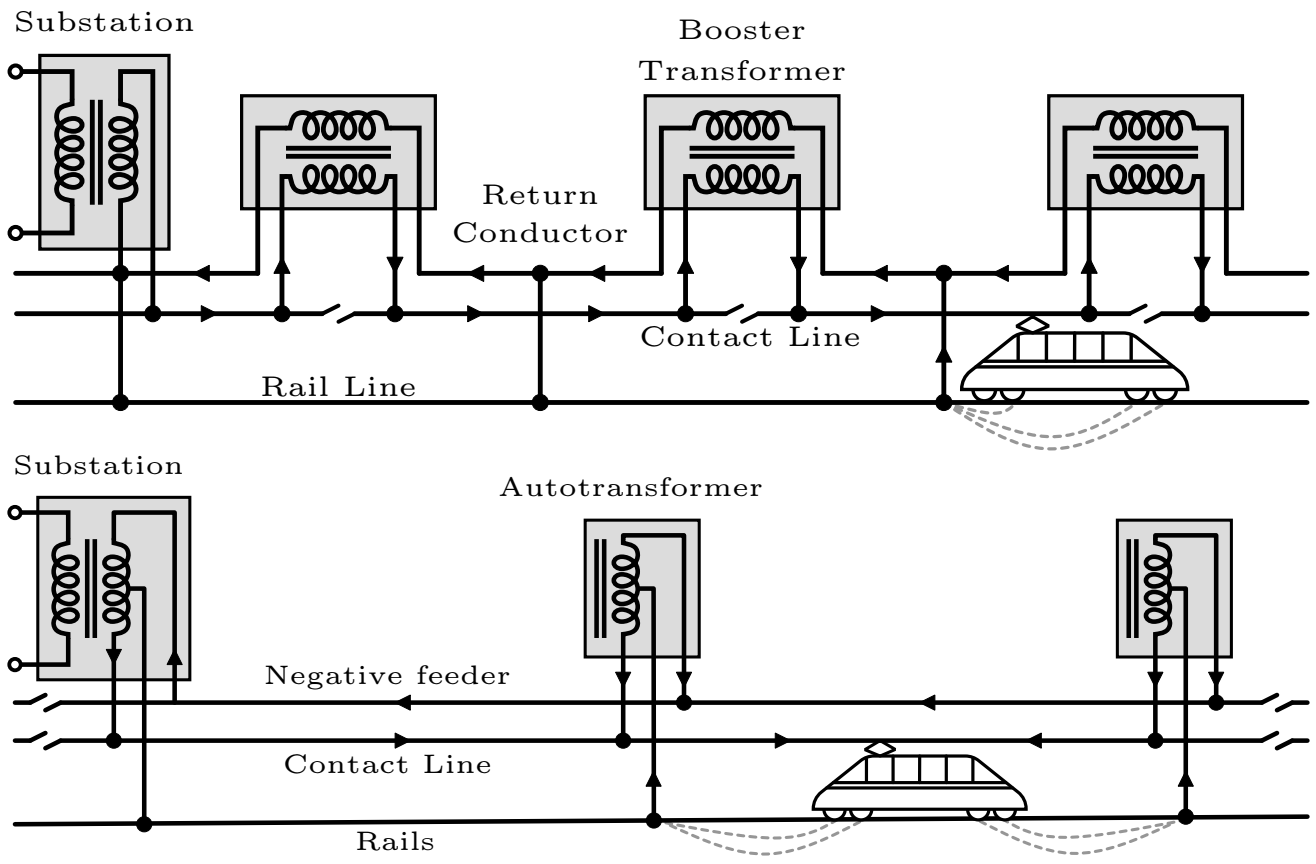

Fig. 7. Single level (top) and bi-level (bottom) voltage distribution in AC traction networks

solution proposal works about power electronics and other devices, and Hardware-In-the-Loop applications.

1) Planning/Operation Methods Using Optimisation Techniques: Even when optimisation methodologies are common in DC traction systems, only a few works in AC traction networks are available. One of the most common applications is the optimal allocation of resources. Examples in [95] and [96] present an optimisation problem combining multi-train simulation called HAMLET railway simulator with genetic algorithms to determine the best positions for the substations, neutral zones, autotransformers, etc. The authors consider environmental factors, prohibited zones or accessibility for maintenance.

In [97], a coordination technique for increasing the operation efficiency of high speed railways considering hybrid accumulation (batteries plus ultracaps), PV panels and wind turbines installed at substation level is proposed. All these elements are coordinated to improve the efficiency of the system using a multiperiod optimization technique. This technique is applied to a $169 \mathrm{~km}$ line in the south of Spain, and results are presented for one of the four sections with 4 autotransformers placed each $20 \mathrm{~km}$. The main novelty is the use of a varying step time for the multiperiod optimization to reduce the computational burden. The full simulation day is divided into 454 intervals of different duration and the entire problem is solved in 50 minutes. The energy savings are around $10 \%$ with a cost reduction higher than $32 \%$.

One of the few references that propose a hierarchical coordination method to be applied to real time operation is [98]. Basically, the authors consider two layers, the first one optimise the driving profiles of the trains. These profiles are then used as inputs to coordinate the energy storage devices at substation level to reduce the prize of the electricity. The methodology iterate in real time between the bottom and top layers so it can re-adapt the driving profiles depending on the network conditions. The procedure is described and simulated but it is not tested in a real infrastructure.

2) Power Quality Issues: A classification of the different issues related to power quality that can appear in $\mathrm{AC}$ traction networks is presented in [19]. There are multiple works related to these power quality issues. Many of them simulate and analyze a specific problem and are focused on reproducing the real problem without proposing a specific solution. Among them, the most numerous group of works are those studying the low frequency oscillations in the traction networks. Other works propose solutions to improve the AC network performance and to avoid specific power quality issues. For example, several works propose and describe flexible AC distribution systems (FACDS) embedded in the conventional AC traction networks.

In [99], the authors propose a transient model of the trains and traction substations to study the low frequency voltage fluctuations generated in the system by the use of high speed and heavy-haul trains. The model is implemented using Matlab-Simulink. The influence of the different parameters like catenary length or traction transformer capacity over the fluctuation are analysed. Something similar is proposed in [100]. In this case a small-signal model is used to study a $2 \times 25 \mathrm{kV}$ network and a train. With the proposed model, it is possible to observe the effect of the different parameters in the Bode diagram representing the whole system. The study concludes that (Electrical Multiple Units) EMU's traction network cascade system impedance ratio is the main influence factor for the instability. Other similar small signal studies were proposed like in [101]. In [102] a method is developed to estimate the network impedance in the train converter level and thus adapt the control to reduce the low frequency oscillations in the network. In [103] and [104], a detailed model for 


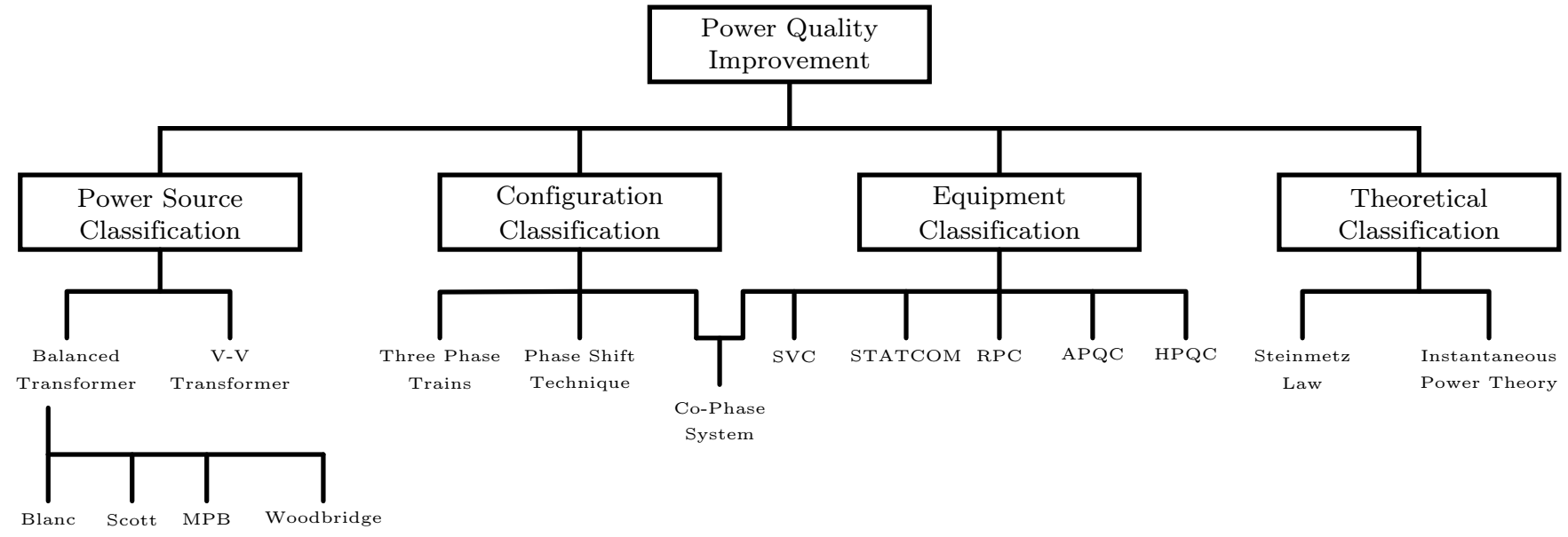

Fig. 8. Power quality improvement strategies classification (extracted from [19]).

studying low frequency oscillations, harmonic resonance and harmonic stability issues is described for $2 \times 25 \mathrm{kV}$ high speed systems. The trains are modelled using the Norton current equivalent, while the utility power sources are modeled using a Thevenin equivalent voltage sources. The geometry of the feeding conductors and rails is considered and the train control is implemented using the dq reference frame. First, the theoretical considerations about the models for the specific studies are explained. Then, the influence of the different factors over the train and the network behaviour are studied. [105] uses a dynamic simulation to study the effect of the regenerative braking of the high-speed trains over the unbalance of the main grid considering different substations power transformer configurations like V/V or SCOT. Finally, [106] presents a very detailed dynamical model with EMTPATP for studying a very specific problem. How switching in the main $\mathrm{AC}$ grid in a $\mathrm{AC}$ low frequency system at $16.7 \mathrm{~Hz}$ affect to the autotransformer transients in bilevel AC traction networks. Trains are not considered in this study and detailed simulations of the transient voltages in the catenary and autotransformers under no-load conditions are provided.

Regarding static studies based in power flow formulation for analysing power quality issues, [107] presents a model of a simplified high speed railway power system to carry out the power flow studies and analyse the variation of the power factor at substation level. The authors consider the variation of the train power factor depending on the train conditions. The effects of the schedules, number of trains, headway and other factors in the substation power factor are also studied. In addition, a tool based on Matlab and Labview is used to represent the results. Another static study presented in [108] and developed with Modelica language is applied to high speed railways and is able to consider all possible paths of the return current through ground, rails and other ground conductors. The proposed model is designed to be applied in power quality and power-frequency studies. In [109], a complete and complex model is developed to assess power quality issues in the traction network as well as in the utility grid. A particularly detailed model of the Scott-connection transformers is proposed. The impact of the schedule variations during a period of 24 hours on the harmonic behaviour is studied. An harmonic power flow, considering the coupling between the train models and the substations, is presented. However, overvoltage and overcurrent protections are not considered. Another work proposes a EMTP model to determine the current distribution in the different wires of the overhead feeding system as well as the rails [110]. This current distribution affects to the couplings with the surrounding metallic structures. It is a detailed model for a very specific purpose. The paper does not consider complex train schedule or realistic scenario, just a constant current injection to evaluate the distribution among the wires. In addition, the authors simulate also a lightning stroke. Finally, [111] proposes a method to calculate the so called Power Supply Capacity (PSC) of the feeding systems by means of repeated power flows of a simplified scheme obtained by means of the Thevenin equivalent. It proposes the creation of a power-voltage curve for each train in order to evaluate how the train power impact over the system. The power limit that each train can demand is calculated depending on the position of the train for two different scenarios. All the studied scenarios considered trains absorbing power from the traction network. There is no complex scenario considering different trains injecting and absorbing power at the same time.

Regarding fault analysis, only a few works have been published during last years. An example can be found in [112] where an analytical formulation is presented to obtain the self and mutual impedances of the $2 \times 25 \mathrm{AC}$ feeding systems. Then, the authors use the obtained impedances to implement a static model and estimate and analyse the currents and voltages obtained with this model when compared with a simplified one proposed in [113]. This second work was specifically proposed for short circuit analysis. The former is used for calculating normal operating conditions and short circuit analysis. The model is quite complex so the cases analysed are reduced to single instant analysis. In [114], a detailed Matlab-Simulink model of an AC railway power system using a Leblanc connection power transformer is presented. The obtained results were verified with field data. Specific time intervals have been studied to check the fault 


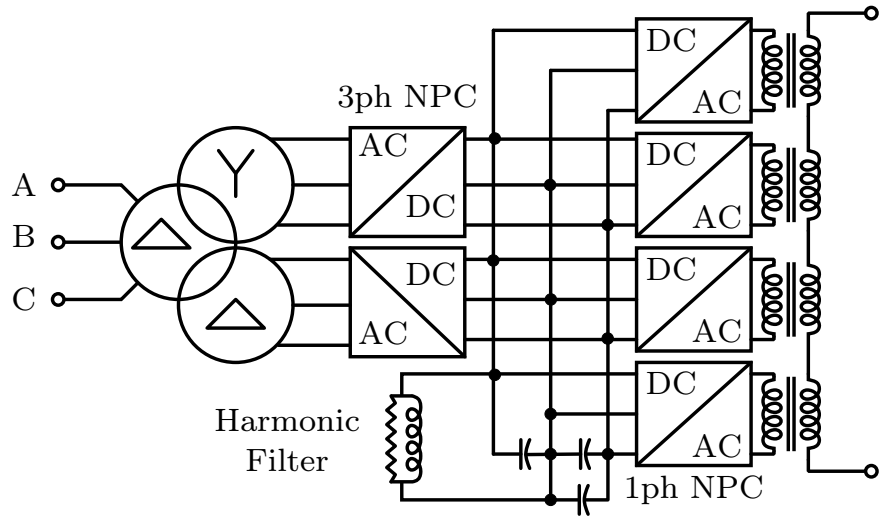

Fig. 9. High-power back to back converter with single DC link and multilevel neutral point clamped (NPC) bridges as described in [17].

currents without running long simulations with a multi-train approach.

3) Solution Proposal Works, Power Electronics and Other Devices: There are a set of works that propose the use of flexible AC distribution system devices to improve the system behaviour or overcome power quality issues. A review of different power electronics solutions applied to the AC railway distribution systems is given in [17]. In Fig. 8] a list of methods used for improve power quality is presented. As an example, in Fig. 9 a novel configuration for feeding single voltage AC system with a high-power back to back converter with a single DC link and three-level neutral point clamped (NPC) bridges is presented. A comparison between the Static Var Compensator and the STATCOM, and between the Full-power converter and the co-phase supply is presented. It is a very descriptive paper with some dynamic simulations but no mathematical models. In [115], a specific compensator is proposed for $25 \mathrm{kV}$ systems fed through YN/VD balance transformers. The aim is the harmonics suppression and reactive power compensation. The proposed topology does not require step-down transformer to connect the compensator to the grid. In [116] and [117], it is proposed the use of a FACDS device in the AC feeding substations using a YN/VD connected balance transformers. The proposed topology is different from the traditional railway static power conditioners. Indeed, the device contains a set of multiple back-to-back converters connected to the feeder using a coupling transformer. The case presented in [118], proposes to install a power electronic device in the $2 \times 25 \mathrm{kV}$ railway systems to reduce the unbalances, improve the power flow management, provide reactive power, and increase the power quality in general. The topology of the so called energy optimisation controller is based also in a back to back converter that can be installed at substation level but also connecting deadzones. A transient simulation of a co-phase traction power supply system, that combines a single phase traction transformer and an active power flow controller, is presented in [119]. Simulation results are presented to verify the compensation capacity on the primary currents of the proposed solution. The work proposed in $[120]$ is interesting since the authors propose a simple device in which they add a power converter to the traditional YN/VD power transformer that feed the conventional single level $25 \mathrm{kV}$ AC railway systems. Two of the delta connected windings of the power transformer are split, so the three phase power converter can be connected to the middle point of these windings. This topology does not need any auxiliar transformer and the authors propose a fully developed compensation technique based in negative sequence current injection to reduce the unbalances in the primary side. The works presented in [121] and [122] are organized in two parts. The first one is focused on the improvements from the point of view of performance that can be achieved connecting the dead zones of the $\mathrm{AC}$ railways by means of $\mathrm{AC} / \mathrm{AC}$ converters called rail power conditioners (RPC). The second part combines RPC with wayside energy storage systems and proposes a methodology to estimate the optimum capacity of the storage system. Static simulations are performed by means of the DigSilent PowerFactory with a step time of $10 \mathrm{~s}$. The authors tested the system with a three days simulation of a $25 \mathrm{kV}$ system of $100 \mathrm{~km}$ in Queensland to determine if it would be possible to disconnect one of the traction substations. Results were very promising in terms of cost savings obtained from elimination of traction substations. The work proposed in [20] is not based specifically in FACDS, but it is worthy to mentioned since multiple topologies for replacing the conventional power transformer inside the trains with a power electronic device have been reviewed.

4) Hardware in the Loop Applications: Related to $\mathrm{AC}$ traction networks we find two works. In [123], HIL hardware is used in order to simulate the feeding infrastructure and analyse the effect of the harmonics in the train controls. The model is developed to study frequencies between 0 and $5 \mathrm{kHz}$ in a $25 \mathrm{kV} 50 \mathrm{~Hz}$ system. The work is not intended to be use for energetic studies, it considers a single train and a single substation. The work developed in $[124]$ is a very detailed analysis of a railway power flow controller in an AC network connecting the two sections fed by the same substation. The real-time HIL laboratory is developed to analyse and test the proposed modified model predictive control method in order improve the system controllability and to compensate the negative sequence currents, suppress harmonics, and alleviate the rms current tracking error.

\section{Conclusions}

In the present paper, the last simulation methods applied to railway traction networks were presented. As it can be observed the irruption of new technologies like energy storage systems or new power electronic devices, triggered a large number of new investigations and research works in this field. As it was demonstrated, the largest group of works are focused on DC traction networks but there is also a significant set of papers related to AC systems. The works are focused on the development of new simulation methodologies and tools but there are also several authors that uses existing tools in order to make very detailed analysis of specific cases of study. Several works related to real time operation are also developed but most of them propose frameworks that are not implemented in real life. Only a few works show already deployed projects or software suites. 
As a final conclusion, it can be stated that all technologies applied to develop the concept of smart grid in conventional distribution systems, are reaching now, with a small delay, the traction networks. In the following years and decades, a big effort should be done to transform the existing traction feeding system in a real smart traction grids. This paper therefore aims to help new researchers starting in this field or senior researchers who want to have a clear perspective of the latest advances in railway traction networks simulation.

\section{REFERENCES}

[1] D. Serrano-Jiménez, L. Abrahamsson, S. Castaño-Solís, and J. SanzFeito, "Electrical Railway Power Supply Systems: Current Situation and Future Trends," International Journal of Electrical Power and Energy Systems, vol. 92, pp. 181-192, 2017.

[2] F. Kiessling, R. Puschmann, A. Schmieder, and E. Schneider, Contact Lines for Electric Railways: Planning, Design, Implementation, Maintenance. Wiley, 2018.

[3] Siemens, "PSS - SINCAL," 2020. [Online]. Available: https://new.siemens.com/global/en/products/energy/services/ transmission-distribution-smart-grid/consulting-and-planning/ pss-software/pss-sincal.html

[4] Anylogic, "Rail Simulation Software," 2020. [Online]. Available: https://www.anylogic.com/rail-logistics/

[5] Berkeley Simulation Software LLC., "Rail Traffic Controller (RTC)," 2019. [Online]. Available: http://berkeleysimulation.com/

[6] InControl Simulation Software, "Simulation of railway networks," 2019. [Online]. Available: https://www.incontrolsim.com/ application-areas/railway-simulation/

[7] MACOMI, "RilGenie - Railway Simulation Software," 2019. [Online]. Available: https://macomi.nl/railway-simulation//

[8] HATCH Ltd., "Hatch Rail Optimizer," 2019. [Online]. Available: https://www.hatch.com/en/Expertise/Services-and-Technologies/ Rail-Optimizer

[9] ESI Group, "SimulationX," 2020. [Online]. Available: https://www. simulationx.com/industries/simulation-railways.html

[10] OpenTrack Railway Technology Ltd., "Opentrack," 2020. [Online]. Available: www.opentrack.ch

[11] Institut für Bahntechnik GmbH, "OpenPowerNet," 2019. [Online]. Available: https://www.openpowernet.com/

[12] SYSTRA, "Railsym X," 2019. [Online]. Available: https://www. systrausa.com/en/technology/smart-tools/article/railsim-X-c

[13] SIGNON Deutchland GmbH, "Sinanet and Webanet Software Packages," 2019. [Online]. Available: https://www.elbas.de/ sinanetwebanet e.html

[14] Operation Technology Inc., "eTraX - Railway Traction Power Solution," 2020. [Online]. Available: https://etap.com/solutions/ railways

[15] - " "eTap - Electrical Power System Analysis Operation Software," 2020. [Online]. Available: https://etap.com

[16] SH Rail, "Traferr - rail electrical traction and power systems simulation," 2020. [Online]. Available: http://www.rail-simulators. com/traferr-energy-consumption-simulator/

[17] I. Krastev, P. Tricoli, S. Hillmansen, and M. Chen, "Future of Electric Railways: Advanced Electrification Systems with Static Converters for ac Railways," IEEE Electrification Magazine, vol. 4, no. 3, pp. 6-14, 2016.

[18] F. Meishner and D. U. Sauer, "Wayside Energy Recovery Systems in DC Urban Railway Grids," eTransportation, vol. 1, 2019.

[19] S. M. Mousavi Gazafrudi, A. Tabakhpour Langerudy, E. F. Fuchs, and K. Al-Haddad, "Power Quality Issues in Railway Electrification: A Comprehensive Perspective," IEEE Transactions on Industrial Electronics, vol. 62, no. 5, pp. 3081-3090, may 2015.

[20] J. Feng, W. Q. Chu, Z. Zhang, and Z. Q. Zhu, "Power Electronic Transformer-Based Railway Traction Systems: Challenges and Opportunities," IEEE Journal of Emerging and Selected Topics in Power Electronics, vol. 5, no. 3, pp. 1237-1253, 2017.

[21] D. Hasegawa, G. L. Nicholson, C. Roberts, and F. Schmid, "Standardised approach to energy consumption calculations for highspeed rail," IET Electrical Systems in Transportation, vol. 6, no. 3, pp. 179-189, 2016.

[22] D. Ronanki, S. A. Singh, and S. S. Williamson, "Comprehensive topological overview of rolling stock architectures and recent trends in electric railway traction systems," IEEE Transactions on Transportation Electrification, vol. 3, no. 3, pp. 724-738, 2017.
[23] H. Chen and B. Jiang, "A review of fault detection and diagnosis for the traction system in high-speed trains," IEEE Transactions on Intelligent Transportation Systems, vol. 21, no. 2, pp. 450-465, 2020.

[24] F. Chen, N. Taylor, and N. Kringos, "Electrification of roads: Opportunities and challenges," Applied Energy, vol. 150, pp. $109-$ 119, 2015.

[25] J. Yin, T. Tang, L. Yang, J. Xun, Y. Huang, and Z. Gao, "Research and development of automatic train operation for railway transportation systems: A survey," Transportation Research Part C: Emerging Technologies, vol. 85, pp. 548 - 572, 2017.

[26] G. M. Scheepmaker, R. M. Goverde, and L. G. Kroon, "Review of energy-efficient train control and timetabling," European Journal of Operational Research, vol. 257, no. 2, pp. 355 - 376, 2017.

[27] T. Kulworawanichpong, "Multi-Train Modeling and Simulation Integrated With Traction Power Supply Solver Using Simplified Newton-Raphson Method," Journal of Modern Transportation, vol. 23 no. 4, pp. 241-251, 2015.

[28] P. Arboleya, B. Mohamed, C. González-Morán, and I. El-Sayed, "BFS Algorithm for Voltage-Constrained Meshed DC Traction Networks With Non-smooth Voltage-Dependent Loads and Generators," IEEE Transactions on Power Systems, vol. 31, no. 2, pp. 1526-1536, 2016.

[29] Z. Tian, S. Hillmansen, C. Roberts, P. Weston, N. Zhao, L. Chen, and M. Chen, "Energy Evaluation of the Power Network of a DC Railway System with Regenerating Trains," IET Electrical Systems in Transportation, vol. 6, no. 2, pp. 41-49, 2016.

[30] B. Mohamed, P. Arboleya, and C. González-Morán, "Modified Current Injection Method for Power Flow Analysis in HeavyMeshed DC Railway Networks with Non-reversible Substations," IEEE Transactions on Vehicular Technology, vol. 66, no. 9, pp. 7688-7696, 2017.

[31] B. Ku and J. Liu, "Modelling and Numerical Solution of Ungrounded DC Rail Traction System Load Flow Using a Ladder Circuit - Part I: Circuit Modelling," IET Generation, Transmission Distribution, vol. 14, no. 1 , pp. $1-10,2020$.

[32] _ - "Modelling and Numerical Solution of Ungrounded DC rail Traction System Load Flow Using Ladder Circuit - Part II: Solution Method," IET Generation, Transmission Distribution, vol. 14, no. 1, pp. 11-20, 2020.

[33] R. A. Jabr and I. Džafić, "Solution of DC Railway Traction Power Flow Systems Including Limited Network Receptivity," IEEE Transactions on Power Systems, vol. 33, no. 1, pp. 962-969, 2018.

[34] Y. Cai, M. R. Irving, and S. H. Case, "Iterative Techniques for the Solution of Complex DC-Rail-Traction Systems Including Regenerative Braking," Generation, Transmission and Distribution, IEE Proceedings-, vol. 142, no. 5, pp. 445-452, sep 1995.

[35] — " "Modelling and Numerical Solution of Multibranched DC Rail Traction Power Systems," Electric Power Applications, IEE Proceedings, vol. 142, no. 5, pp. 323-328, 1995.

[36] G. Zhang, Z. Tian, P. Tricoli, S. Hillmansen, Y. Wang, and Z. Liu, "Inverter Operating Characteristics Optimization for DC Traction Power Supply Systems," IEEE Transactions on Vehicular Technology, vol. 68, no. 4, pp. 3400-3410, 2019.

[37] P. Arboleya, B. Mohamed, and I. El-Sayed, "DC Railway Simulation Including Controllable Power Electronic and Energy Storage Devices," IEEE Transactions on Power Systems, vol. 33, no. 5, pp. 5319-5329, Sep. 2018.

[38] H.-S. Go, I.-H. Cho, G.-D. Kim, and C.-H. Kim, "Reduction of Electricity Prices Using the Train to Grid (T2G) System in Urban Railway," Energies, vol. 11, no. 3, 2018.

[39] G. Zhang, Z. Tian, P. Tricoli, S. Hillmansen, and Z. Liu, "A New Hybrid Simulation Integrating Transient-State and Steady-State Models for the Analysis of Reversible DC Traction Power Systems," International Journal of Electrical Power and Energy Systems, vol. 109, pp. 9-19, jul 2019.

[40] F. Hao, G. Zhang, J. Chen, Z. Liu, D. Xu, and Y. Wang, "Optimal Voltage Regulation and Power Sharing in Traction Power Systems with Reversible Converters," IEEE Transactions on Power Systems, pp. 1-1, 2020.

[41] B. Mohamed, I. El-Sayed, and P. Arboleya, "DC Railway Infrastructure Simulation Including Energy Storage and Controllable Substations," in 2018 IEEE Vehicle Power and Propulsion Conference (VPPC), 2018, pp. 1-6.

[42] Z. Yang, Z. Yang, H. Xia, and F. Lin, "Brake Voltage Following Control of Supercapacitor-Based Energy Storage Systems in Metro Considering Train Operation State," IEEE Transactions on Industrial Electronics, vol. PP, no. 99, p. 1, 2018. 
[43] P. Arboleya, I. El-Sayed, B. Mohamed, and C. Mayet, "Modeling, Simulation and Analysis of On-Board Hybrid Energy Storage Systems for Railway Applications," Energies, vol. 12, no. 11, 2019.

[44] L. Alfieri, L. Battistelli, and M. Pagano, "Energy efficiency strategies for railway application: alternative solutions applied to a real case study," IET Electrical Systems in Transportation, vol. 8, no. 2, pp. 122-129, 2018.

[45] A. M. Gee and R. W. Dunn, "Analysis of Trackside Flywheel Energy Storage in Light Rail Systems," IEEE Transactions on Vehicular Technology, vol. 64, no. 9, pp. 3858-3869, 2015.

[46] L. Alfieri, L. Battistelli, and M. Pagano, "Impact on Railway Infrastructure of Wayside Energy Storage Systems for Regenerative Braking Management: a Case Study on a Real Italian Railway Infrastructure," IET Electrical Systems in Transportation, 2019.

[47] A. Ogunsola, L. Sandrolini, and A. Mariscotti, "Evaluation of Stray Current From a DC-Electrified Railway With Integrated Electric-Electromechanical Modeling and Traffic Simulation," IEEE Transactions on Industry Applications, vol. 51, no. 6, pp. 5431-5441, nov 2015.

[48] A. Ibrahem, A. Elrayyah, Y. Sozer, and J. A. D. Abreu-Garcia "DC Railway System Emulator for Stray Current and Touch Voltage Prediction," IEEE Transactions on Industry Applications, vol. 53, no. 1, pp. 439-446, 2017.

[49] P. Arboleya, "Heterogeneous Multiscale Method for Multirate Railway Traction Systems Analysis," IEEE Transactions on Intelligent Transportation Systems, vol. 18, no. 9, pp. 2575-2580, 2017.

[50] C. Mayet, A. Bouscayrol, P. Delarue, E. Chattot, and J. N. Verhille, "Electrokinematical Simulation for Flexible Energetic Studies of Railway Systems," IEEE Transactions on Industrial Electronics, vol. 65 , no. 4, pp. 3592-3600, 2018.

[51] X. Zhu, H. Hu, H. Tao, and Z. He, "Stability Analysis of PV PlantTied MVDC Railway Electrification System," IEEE Transactions on Transportation Electrification, vol. 5, no. 1, pp. 311-323, 2019.

[52] M. Khodaparastan, O. Dutta, M. Saleh, and A. A. Mohamed, "Modeling and Simulation of DC Electric Rail Transit Systems With Wayside Energy Storage," IEEE Transactions on Vehicular Technology, vol. 68 , no. 3, pp. 2218-2228, 2019.

[53] A. Clerici, E. Tironi, and F. Castelli-Dezza, "Multiport Converters and ESS on 3-kV DC Railway Lines: Case Study for Braking Energy Savings," IEEE Transactions on Industry Applications, vol. 54, no. 3, pp. 2740-2750, may 2018.

[54] C. Mayet, P. Delarue, A. Bouscayrol, E. Chattot, and J. N. Verhille, "Comparison of Different EMR-Based Models of Traction Power Substations for Energetic Studies of Subway Lines," IEEE Transactions on Vehicular Technology, vol. 65, no. 3, pp. 1021-1029, mar 2016.

[55] A. Zaboli, B. Vahidi, S. Yousefi, and M. M. Hosseini-Biyouki, "Evaluation and Control of Stray Current in DC-Electrified Railway Systems," Vehicular Technology, IEEE Transactions on, vol. PP, no. 99 , p. $1,2016$.

[56] A. González-Gil, R. Palacin, and P. Batty, "Optimal Energy Management of Urban Rail Systems: Key Performance Indicators," Energy Conversion and Management, vol. 90, pp. 282-291, 2015.

[57] Z. Tian, N. Zhao, S. Hillmansen, C. Roberts, T. Dowens, and C. Kerr, "SmartDrive: Traction Energy Optimization and Applications in Rail Systems," IEEE Transactions on Intelligent Transportation Systems, vol. 20, no. 7, pp. 2764-2773, 2019.

[58] W. ShangGuan, X. Yan, B. Cai, and J. Wang, "Multiobjective Optimization for Train Speed Trajectory in CTCS High-Speed Railway With Hybrid Evolutionary Algorithm," IEEE Transactions on Intelligent Transportation Systems, vol. 16, no. 4, pp. 2215-2225, 2015.

[59] L. Chen, C. Roberts, F. Schmid, and E. Stewart, "Modeling and Solving Real-Time Train Rescheduling Problems in Railway Bottleneck Sections," IEEE Transactions on Intelligent Transportation Systems, vol. 16, no. 4, pp. 1896-1904, 2015.

[60] P. Liu, L. Yang, Z. Gao, Y. Huang, S. Li, and Y. Gao, "Energy-Efficient Train Timetable Optimization in the Subway System with Energy Storage Devices," IEEE Transactions on Intelligent Transportation Systems, vol. 19, no. 12, pp. 3947-3963, 2018.

[61] H. Liu, M. Zhou, X. Guo, Z. Zhang, B. Ning, and T. Tang, "Timetable Optimization for Regenerative Energy Utilization in Subway Systems," IEEE Transactions on Intelligent Transportation Systems, pp. 1-11, 2018.

[62] S. Su, T. Tang, and C. Roberts, "A Cooperative Train Control Model for Energy Saving," IEEE Transactions on Intelligent Transportation Systems, vol. 16, no. 2, pp. 622-631, apr 2015.

[63] X. Zhao, B. Ke, and K. Lian, "Optimization of Train Speed Curve for Energy Saving Using Efficient and Accurate Electric Traction
Models on the Mass Rapid Transit System," IEEE Transactions on Transportation Electrification, vol. 4, no. 4, pp. 922-935, Dec 2018.

[64] A. J. López-López, R. R. Pecharromán, A. Fernández-Cardador, and A. P. Cucala, "Smart Traffic-Scenario Compressor for the Efficient Electrical Simulation of Mass Transit Systems," International Journal of Electrical Power \& Energy Systems, vol. 88, pp. 150-163, 2017.

[65] W. Jefimowski and A. Szeląg, "The Multi-Criteria Optimization Method for Implementation of a Regenerative Inverter in a $3 \mathrm{kV}$ DC Traction System," Electric Power Systems Research, vol. 161, pp. 6173, 2018.

[66] G. Graber, V. Calderaro, V. Galdi, A. Piccolo, R. Lamedica, and A. Ruvio, "Techno-Economic Sizing of Auxiliary-BatteryBased Substations in DC Railway Systems," IEEE Transactions on Transportation Electrification, vol. 4, no. 2, pp. 616-625, 2018.

[67] D. Roch-Dupré, Á. J. López-López, R. R. Pecharromán, A. P. Cucala, and A. Fernández-Cardador, "Analysis of the Demand Charge in DC Railway Systems and Reduction of Its Economic Impact with Energy Storage Systems," International Journal of Electrical Power \& Energy Systems, vol. 93, pp. 459-467, 2017.

[68] H. Lee, S. Joo, and G. Jang, "CDF-Based Capacity Estimation Method for Stationary Regenerative Solution in Parallel-Fed DC Urban Subway Transit," IEEE Transactions on Sustainable Energy, vol. 11, no. 1, pp. 206-216, Jan 2020.

[69] L. Razik, N. Berr, S. Khayyam, F. Ponci, and A. Monti, "REMS-Railway Energy Management in Real Rail Operation," IEEE Transactions on Vehicular Technology, vol. 68, no. 2, pp. 1266-1277, feb 2019.

[70] D. Roch-Dupré, A. P. Cucala, R. R. Pecharromán, Á. J. López-López, and A. Fernández-Cardador, "Evaluation of the Impact that the Traffic Model Used in Railway Electrical Simulation has on the Assessment of the Installation of a Reversible Substation," International Journal of Electrical Power \& Energy Systems, vol. 102, pp. 201-210, 2018

[71] R. Takagi and T. Amano, "Optimisation of Reference State-ofCharge Curves for the Feed-Forward Charge/Discharge Control of Energy Storage Systems On-Board DC Electric Railway Vehicles," IET Electrical Systems in Transportation, vol. 5, no. 1, pp. 33-42, 2015.

[72] P. Arboleya, P. Bidaguren, and U. Armendariz, "Energy Is on Board: Energy Storage and Other Alternatives in Modern Light Railways,' IEEE Electrification Magazine, vol. 4, no. 3, pp. 30-41, 2016.

[73] A. Ovalle, J. Pouget, S. Bacha, L. Gerbaud, E. Vinot, and B. Sonier, "Energy Storage Sizing Methodology for Mass-Transit Direct-Current Wayside Support: Application to French Railway Company Case Study," Applied Energy, vol. 230, pp. 1673 - 1684, 2018.

[74] F. Naseri, E. Farjah, Z. Kazemi, E. Schaltz, T. Ghanbari, and J. Schanen, "Dynamic Stabilization of DC Traction Systems Using a Supercapacitor-Based Active Stabilizer with Model Predictive Control," IEEE Transactions on Transportation Electrification, pp. 1-1, 2020.

[75] A. Fernández-Rodríguez, A. Fernández-Cardador, A. P. Cucala, and M. C. Falvo, "Energy Efficiency and Integration of Urban Electrical Transport Systems: EVs and Metro-Trains of Two Real European Lines," Energies, vol. 12, no. 3, p. 316, 2019.

[76] S. Khayyam, F. Ponci, J. Goikoetxea, V. Recagno, V. Bagliano, and A. Monti, "Railway Energy Management System: Centralized-Decentralized Automation Architecture," IEEE Transactions on Smart Grid, vol. 7, no. 2, pp. 1164-1175, 2016.

[77] S. Khayyam, N. Berr, L. Razik, M. Fleck, F. Ponci, and A. Monti, "Railway System Energy Management Optimization Demonstrated at Offline and Online Case Studies," IEEE Transactions on Intelligent Transportation Systems, vol. 19, no. 11, pp. 3570-3583, nov 2018.

[78] Y. Bai, Y. Cao, Z. Yu, T. K. Ho, C. Roberts, and B. Mao, "Cooperative Control of Metro Trains to Minimize Net Energy Consumption," IEEE Transactions on Intelligent Transportation Systems, pp. 1-15, 2019.

[79] X. Sun, H. Lu, and H. Dong, "Energy-Efficient Train Control by Multi-Train Dynamic Cooperation," IEEE Transactions on Intelligent Transportation Systems, vol. 18, no. 11, pp. 3114-3121, nov 2017.

[80] F. Ciccarelli, D. Iannuzzi, K. Kondo, and L. Fratelli, "Line-Voltage Control Based on Wayside Energy Storage Systems for Tramway Networks," IEEE Transactions on Power Electronics, vol. 31, no. 1, pp. 884-899, 2016.

[81] V. A. Kleftakis and N. D. Hatziargyriou, "Optimal Control of Reversible Substations and Wayside Storage Devices for Voltage Stabilization and Energy Savings in Metro Railway Networks," IEEE Transactions on Transportation Electrification, vol. 5, no. 2, pp. 515523, 2019

[82] S. Boudoudouh and M. Maaroufi, "Renewable Energy Sources Integration and Control in Railway Microgrid," IEEE Transactions on Industry Applications, vol. 55, no. 2, pp. 2045-2052, 2019. 
[83] I. Şengör, H. C. Kılıçkıran, H. Akdemir, B. Kekezoğlu, O. Erdinç, and J. P. S. Catalão, "Energy Management of a Smart Railway Station Considering Regenerative Braking and Stochastic Behaviour of ESS and PV Generation," IEEE Transactions on Sustainable Energy, vol. 9, no. 3, pp. 1041-1050, 2018.

[84] Q. Li, T. Wang, C. Dai, W. Chen, and L. Ma, "Power Management Strategy Based on Adaptive Droop Control for a Fuel Cell-BatterySupercapacitor Hybrid Tramway," IEEE Transactions on Vehicular Technology, vol. 67, no. 7, pp. 5658-5670, 2018.

[85] Y. J. Oh, J. Lee, H. Liu, S. Cho, J. Lee, and H. Lee, "Hardware-in-theLoop Simulation for Active Control of Tramcars With Independently Rotating Wheels," IEEE Access, vol. 7, pp. 71 252-71 261, 2019.

[86] C. Mayet, P. Delarue, A. Bouscayrol, and E. Chattot, "HardwareIn-the-Loop Simulation of Traction Power Supply for Power Flows Analysis of Multitrain Subway Lines," IEEE Transactions on Vehicular Technology, vol. 66, no. 7, pp. 5564-5571, 2017.

[87] K. Higashikawa, S. Urasaki, M. Inoue, M. Tomita, and T. Kiss, "Hardware-in-the-Loop Simulation of Superconducting Devices for DC Electric Railway Systems Based on a Real-Time Digital Simulator," IEEE Transactions on Applied Superconductivity, vol. 26, no. 4, pp. $1-4,2016$.

[88] X. Yang, H. Hu, Y. Ge, S. Aatif, Z. He, and S. Gao, "An Improved Droop Control Strategy for VSC-Based MVDC Traction Power Supply System," IEEE Transactions on Industry Applications, vol. 54, no. 5, pp. 5173-5186, sep 2018.

[89] A. Verdicchio, P. Ladoux, H. Caron, and C. Courtois, "New MediumVoltage DC Railway Electrification System," IEEE Transactions on Transportation Electrification, vol. 4, no. 2, pp. 591-604, 2018

[90] E. Pilo, S. K. Mazumder, and I. González-Franco, "Smart Electrical Infrastructure for AC-Fed Railways With Neutral Zones," IEEE Transactions on Intelligent Transportation Systems, vol. 16, no. 2, pp. 642-652, 2015.

[91] P. Arboleya, B. Mohamed, I. El-Sayed, and C. Gonzalez-Moran, "High-Speed 2x25kV Traction System Model and Solver for Extensive Network Simulations," IEEE Transactions on Power Systems, p. 1, 2019.

[92] Y. Chen, R. White, T. Fella, S. Hillmansen, and P. Weston, "MultiConductor Model for AC Railway Train Simulation," IET Electrical Systems in Transportation, vol. 6, no. 2, pp. 67-75, 2016.

[93] K. Mongkoldee and T. Kulworawanichpong, "Current-Based NewtonRaphson Power Flow Calculation for AT-Fed Railway Power Supply Systems," International Journal of Electrical Power and Energy Systems, vol. 98, pp. 11-22, 2018.

[94] M. Shafighy, S. Khoo, and A. Z. Kouzani, "Modelling and Simulation of Regeneration in AC Traction Propulsion System of Electrified Railway," IET Electrical Systems in Transportation, vol. 5, no. 4, pp. $145-155,2015$.

[95] M. Soler, J. Lopez, J. M. M. S. de Pedro, and J. Maroto, "Methodology for Multiobjective Optimization of the AC Railway Power Supply System," IEEE Transactions on Intelligent Transportation Systems, vol. 16, no. 5, pp. 2531-2542, oct 2015.

[96] M. Soler-Nicolau, J. M. Mera, J. López, and J. D. Cano-Moreno, "Improving Power Supply Design for High Speed Lines and 2x25kV Systems Using a Genetic Algorithm," International Journal of Electrical Power and Energy Systems, vol. 99, pp. 309-322, 2018.

[97] J. A. Aguado, A. J. S. Racero, and S. de la Torre, "Optimal Operation of Electric Railways With Renewable Energy and Electric Storage Systems," IEEE Transactions on Smart Grid, vol. 9, no. 2, pp. 993 $1001,2018$.

[98] H. Novak, V. Lešić, and M. Vašak, "Hierarchical Model Predictive Control for Coordinated Electric Railway Traction System Energy Management," IEEE Transactions on Intelligent Transportation Systems, vol. 20, no. 7, pp. 2715-2727, 2019.

[99] X. Jiang, H. Hu, Z. He, H. Tao, and Q. Qian, "Study on Low-Frequency Voltage Fluctuation of Traction Power Supply System Introduced by Multiple Modern Trains," Electric Power Systems Research, vol. 146, pp. 246-257, 2017.

[100] Z. Liu, G. Zhang, and Y. Liao, "Stability Research of High-Speed Railway EMUs and Traction Network Cascade System Considering Impedance Matching," IEEE Transactions on Industry Applications, vol. 52, no. 5, pp. 4315-4326, 2016.

[101] H. Wang, W. Mingli, and J. Sun, "Analysis of Low-Frequency Oscillation in Electric Railways Based on Small-Signal Modeling of Vehicle-Grid System in dq Frame," IEEE Transactions on Power Electronics, vol. 30, no. 9, pp. 5318-5330, 2015.
[102] P. Pan, H. Hu, X. Yang, F. Blaabjerg, X. Wang, and Z. He, "Impedance Measurement of Traction Network and Electric Train for Stability Analysis in High-Speed Railways," IEEE Transactions on Power Electronics, vol. 33, no. 12, pp. 10086-10 100, 2018.

[103] H. Hu, H. Tao, F. Blaabjerg, X. Wang, Z. He, and S. Gao, "Train Network Interactions and Stability Evaluation in High-Speed Railways Part I: Phenomena and Modeling," IEEE Transactions on Power Electronics, vol. 33, no. 6, pp. 4627-4642, 2018.

[104] H. Hu, H. Tao, X. Wang, F. Blaabjerg, Z. He, and S. Gao, "Train Network Interactions and Stability Evaluation in High-Speed Railways Part II: Influential Factors and Verifications," IEEE Transactions on Power Electronics, vol. 33, no. 6, pp. 4643-4659, 2018.

[105] J. Yuan, F. Xiao, C. Zhang, Y. Chen, Z. Ni, and Y. Zhong, "Collaborative Unbalance Compensation Method for High-Speed Railway Traction Power Supply System Considering Energy Feedback," IET Power Electronics, vol. 12, no. 1, pp. 129-137, jan 2019.

[106] T. Chmielewski, P. Oramus, and K. Koska, "Switching Transients in a $2 \times 15 \mathrm{kV} 16.7 \mathrm{~Hz}$ Autotransformer Railway System," IET Generation, Transmission Distribution, vol. 12, no. 1, pp. 235-240, 2018.

[107] K. Wang, H. Hu, Z. Zheng, Z. He, and L. Chen, "Study on Power Factor Behavior in High-Speed Railways Considering Train Timetable," IEEE Transactions on Transportation Electrification, vol. 4, no. 1, pp. 220231, 2018.

[108] M. Ceraolo, "Modeling and Simulation of AC Railway Electric Supply Lines Including Ground Return," IEEE Transactions on Transportation Electrification, vol. 4, no. 1, pp. 202-210, 2018.

[109] H. Hu, Z. He, K. Wang, X. Ma, S. Gao, X. Li, K. Wang, and S. Gao, "Power-Quality Impact Assessment for High-Speed Railway Associated With High-Speed Trains Using Train Timetable - Part II: Verifications, Estimations and Applications," IEEE Transactions on Power Delivery, vol. 31, no. 4, pp. 693-703, 2016.

[110] B. Milesevic, B. Filipovic-Grcic, I. Uglesic, and B. Jurisic, "Estimation of Current Distribution in the Electric Railway System in the EMTPRV,” Electric Power Systems Research, vol. 162, pp. 83-88, 2018

[111] J. Zhang, M. Wu, and Q. Liu, "A Novel Power Flow Algorithm for Traction Power Supply Systems Based on the Thévenin Equivalent," Energies, vol. 11, no. 1, p. 126, jan 2018.

[112] S. Minucci, M. Pagano, and D. Proto, "Model of the $2 \times 25 \mathrm{kV}$ High Speed Railway Supply System Taking into Account the Soil-Air Interface," International Journal of Electrical Power \& Energy Systems, vol. 95, pp. 644-652, 2018

[113] L. Battistelli, M. Pagano, and D. Proto, " $2 \times 25 \mathrm{kV} 50 \mathrm{~Hz}$ High-Speed Traction Power System: Short-Circuit Modeling," IEEE Transactions on Power Delivery, vol. 26, no. 3, pp. 1459-1466, 2011.

[114] T. Chen and R. Liao, "Modelling, Simulation, and Verification for Detailed Short-Circuit Analysis of a $1 \times 25 \mathrm{kV}$ Railway Traction System," IET Generation, Transmission Distribution, vol. 10, no. 5, pp. 1124-1135, 2016

[115] G. Cui, L. Luo, Y. Li, C. Liang, S. Hu, B. Xie, J. Xu, Z. Zhang, Y. Liu, and T. Wang, "YN/VD Connected Balance Transformer-Based Hybrid Power Quality Compensator for Harmonic Suppression and Reactive Power Compensation of Electrical Railway Power Systems," International Journal of Electrical Power \& Energy Systems, vol. 113, pp. 481-491, 2019.

[116] Z. Zhang, B. Xie, S. Hu, Y. Li, L. Luo, C. Rehtanz, and O. Krause, "Reactive Power Compensation and Negative-Sequence Current Suppression System for Electrical Railways With YN/VDConnected Balance Transformer-Part I: Theoretical Analysis," IEEE Transactions on Power Electronics, vol. 33, no. 1, pp. 272-282, Jan 2018.

[117] - "Reactive Power Compensation and Negative-Sequence Current Suppression System for Electrical Railways With YN/VD-Connected Balance Transformer-Part II: Implementation and Verification," IEEE Transactions on Power Electronics, vol. 33, no. 12, pp. 272-282, 2017.

[118] Y. Wang, M. Chen, L. Guo, and J. Luo, "Flexible Traction Power System Adopting Energy Optimisation Controller for AC-Fed Railway," Electronics Letters, vol. 53, no. 8, pp. 554-556, 2017.

[119] M. Chen, Q. Li, C. Roberts, S. Hillmansen, P. Tricoli, N. Zhao, and I. Krastev, "Modelling and Performance Analysis of Advanced Combined Co-Phase Traction Power Supply System in Electrified Railway," IET Generation, Transmission Distribution, vol. 10, no. 4, pp. 906-916, 2016.

[120] B. Xie, Z. Zhang, S. Hu, Y. Li, L. Luo, and S. Sun, "YN/VD Connected Balance Transformer-Based Electrical Railway Negative Sequence Current Compensation System With Passive Control Scheme," IET Power Electronics, vol. 9, no. 10, pp. 2044-2051, 2016. 
[121] I. Perin, G. R. Walker, and G. Ledwich, "Load Sharing and Wayside Battery Storage for Improving AC Railway Network Performance, With Generic Model for Capacity Estimation - Part 1," IEEE Transactions on Industrial Electronics, vol. 66, no. 3, pp. 1791-1798, March 2019.

[122] — , "Load Sharing and Wayside Battery Storage for Improving AC Railway Network Performance With Generic Model for Capacity Estimation - Part 2," IEEE Transactions on Industrial Electronics, vol. 65 , no. 12, pp. 9459-9467, 2018.

[123] C. Stackler, N. Evans, L. Bourserie, F. Wallart, F. Morel, and P. Ladoux, "25kV-50 Hz Railway Power Supply System Emulation for Power-Hardware-in-the-Loop Testings," IET Electrical Systems in Transportation, vol. 9, no. 2, pp. 86-92, 2019.

[124] H. J. Kaleybar, H. M. Kojabadi, F. Foiadelli, M. Brenna, and F. Blaabjerg, "Model Analysis and Real-Time Implementation of Model Predictive Control for Railway Power Flow Controller," International Journal of Electrical Power \& Energy Systems, vol. 109, pp. 290-306, 2019.

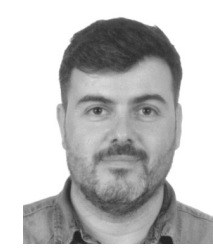

Pablo Arboleya (SM'13) received the M.Sc. and $\mathrm{Ph} . \mathrm{D}$. (with distinction) degrees from the University of Oviedo, Gijón, Spain, in 2001 and 2005, respectively, both in Electrical Engineering. Nowadays, he works as Associate Professor in the Department of Electrical Engineering at the University of Oviedo, he is Managing Editor of the International Journal of Electrical Power and Energy Systems and holder of the Gijón Smart Cities Chair at the University of Oviedo. Presently his main research interests are focused in the micro-grid and smart-grid modeling and operation techniques, Internet of the Energy applications, railway traction networks simulation and combined AC/DC power flow algorithms.

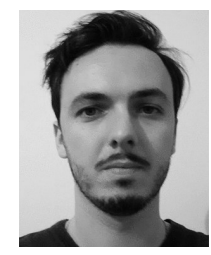

Clément Mayet (M'20) received his Ph.D. degree in Electrical Engineering in 2016 from the University of Lille, France. Then, he held a post-doctoral position at the University of Lille and the L2EP. From 2017 to 2018, he was senior researcher at the MOBI research group at the Vrije Universiteit of Brussels, Belgium. Since September 2018 he is Associate Professor at the Conservatoire National des Arts et Métiers of Paris, France, and the SATIE laboratory. His research interests include graphical descriptions, modelling, control, energy management, and hardware-in-theloop simulation of Electric and Hybrid Vehicles, including railway systems.

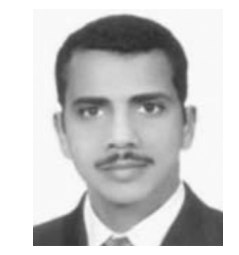

Bassam Mohamed received the M.Sc and Ph.D. degrees from the University of Oviedo, Gijón, Spain, in 2014 and 2018 respectively. Now, he is responsible of railway software development at LEMUR Research Group. His field of expertise has to do with the efficient design and implementation of algorithms for power systems analysis, specially those related to railway networks. During the last years, he developed several commercial software packages for electric network analysis and simulation.

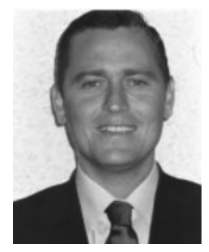

José Antonio Aguado (M'01) received the Electrical Engineer and Ph.D. degrees from the University of Málaga, Málaga, Spain, in 1997 and 2001, respectively. Currently, he is Professor and Head of the Department of Electrical Engineering at the University of Málaga. His research interests include operation, planning, electricity and numerical optimization techniques

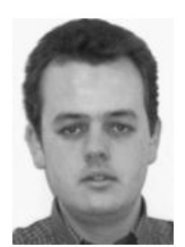

Sebastián de la Torre received the Ingeniero Industrial degree from the Universidad de Málaga, Málaga, Spain, in 1999 and the Ph.D. degree in power systems operations planning at the Universidad de Castilla - La Mancha, Ciudad Real, Spain, in 2003. He is currently Associate Professor at the Department of Electrical Engineering at the Universidad de Málaga. His research interests include operations and economics of electrical energy systems, energy storage and railways. 